\title{
Plasma sgp130 is an independent predictor of non-alcoholic fatty liver disease severity
}

Aysim Gunes ${ }^{1,2,3}$, Laurent Bilodeau ${ }^{4}$, Catherine Huet ${ }^{4}$, Assia Belblidia ${ }^{4}$, Cindy Baldwin ${ }^{1}$, JeanneMarie Giard ${ }^{5}$, Laurent Biertho ${ }^{6,7}$, Annie Lafortune ${ }^{6,7}$, Christian Yves Couture ${ }^{6,8}$, Bich N Nguyen ${ }^{9}$, Eithan Galun ${ }^{10}$, Chantal Bémeur ${ }^{11,12}$, Marc Bilodeau ${ }^{12}$, Mathieu Laplante ${ }^{3,13,14}$, An Tang ${ }^{4}$, May Faraj $^{1,3,11}$, Jennifer L. Estall ${ }^{1,2,3 *}$.

${ }^{1}$ Institut de recherches cliniques de Montréal (IRCM), Montréal, Québec, Canada.

${ }^{2}$ Division of Experimental Medicine, McGill University, Montreal, Quebec, Canada.

${ }^{3}$ Montreal Diabetes Research Centre, Montreal, Quebec, Canada.

${ }^{4}$ Département de radiologie, Centre hospitalier de l'Université de Montréal (CHUM), Montréal, Québec, Canada.

${ }^{5}$ Département d'hépatologie, Centre hospitalier de l'Université de Montréal (CHUM), Département de médecine, Université de Montréal, Centre de recherche du CHUM, Montréal, Québec, Canada.

${ }^{6}$ Centre de recherche de l'Institut Universitaire de cardiologie et de pneumologie de Québec, Université Laval, Québec, Canada.

${ }^{7}$ Département de chirurgie, Faculté de médecine, Université Laval, Québec, Canada.

${ }^{8}$ Département de biologie moléculaire, biochimie médicale et pathologie, Université Laval, Québec, Canada.

${ }^{9}$ Département de pathologie et biologie cellulaire, Université de Montréal, Montréal, Québec, Canada.

${ }^{10}$ Goldyne Savad Institute of Gene Therapy, Hadassah Hebrew University Hospital, Jerusalem, Israel.

${ }^{11}$ Département de nutrition, Université de Montréal, Montréal, Québec, Canada.

${ }^{12}$ Labo HépatoNeuro, Centre de recherche du CHUM, Montréal, Québec, Canada.

${ }^{13}$ Centre de recherche de l'Institut universitaire de cardiologie et de pneumologie de Québec (CRIUCPQ), Faculté de Médecine, Université Laval, Québec, QC, Canada. ${ }^{14}$ Centre de recherche sur le cancer de l’Université Laval, Université Laval, Québec, QC, Canada.

Short Title: Plasma sIL-6R and sgp130 predict liver volume and stiffness in NASH 
Word count: 4497

Number of figures: 3 (6 Supplementary Figures)

Number of tables: 5 (1 Supplementary Table)

*Correspondence and reprint requests should be addressed to:

Jennifer L. Estall, PhD

Institut de Recherches Cliniques de Montreal

110 avenue des Pins Ouest, Montreal, Quebec, H2W 1R7, Canada.

Phone: 5149875688

Email: jennifer.estall@ircm.qc.ca

Disclosure Statement: Laurent Biertho receives funding from Johnson \& Johnson Medical Companies, Medtronic, Bodynov and GI Windows for studies on bariatric surgery. An Tang received a speaking honorarium from Eli Lilly.

Author Contributions: JLE and AT designed studies. $\mathrm{CH}$ and AB managed the NASH clinical study. L Biertho and AL designed and carried out the bariatric surgery study. AT, L Bilodeau, AG and $\mathrm{C}$ Baldwin acquired, analyzed and interpreted data. MF assisted with data analysis. JLE, L Bilodeau, AT, MF, ML, EG, MB, C Bémeur, MF contributed intellectual content. CYC scored liver histological samples. AG. MF and JLE wrote the manuscript. All authors reviewed the manuscript.

Funding: This work was supported by unrestricted operating grants from the Merck, Sharpe and Dohme Corporation/University of Montreal and the International Development Research Centre (108591-001), and program support from the Quebec Ministry of Economy and Innovation. JLE and AT are supported by Chercheurs-boursiers: Senior awards from the Fonds de recherche du Québec - Santé. The ULaval Biobank is supported by the IUCPQ Foundation and Research Center. 
medRxiv preprint doi: https://doi.org/10.1101/2022.01.10.22268968; this version posted January 11, 2022. The copyright holder for this preprint (which was not certified by peer review) is the author/funder, who has granted medRxiv a license to display the preprint in perpetuity. It is made available under a CC-BY-NC-ND 4.0 International license .

Acknowledgements: Authors acknowledge the invaluable collaboration of the surgery team, bariatric surgeons, and biobank staff of the IUCPQ. We would also like to thank Paule Bodson Clermont, Hannah Zhang, Mélissa Léveillé and Stewart Jeromson for their assistance. 


\begin{abstract}
Background: Nonalcoholic steatohepatitis (NASH) is a metabolic disease associated with liver failure and cancer. Accurate monitoring of advancing NASH is challenging. There are few reliable, non-invasive biomarkers of early NASH. Since liver inflammation is a main driver of fibrosis, we investigated relationships between circulating components of the interleukin-6 signaling pathway (IL-6, sIL-6R and sgp130) and liver pathology in subjects with NAFLD and NASH.
\end{abstract}

Methods: Predictive performance of plasma IL-6, sIL-6R and sgp130 were investigated in two independent cohorts: 1) patients with biopsy-confirmed NASH $(n=49)$, where magnetic resonance spectroscopy (MRS), imaging (MRI) and elastography (MRE) assessed liver fat, volume and stiffness; and 2) patients with morbid obesity $(n=245)$ undergoing bariatric surgery where Bedossa algorithm and steatosis, activity, and fibrosis scores assessed NASH severity. Correlations were evaluated between circulating IL-6, sIL-6R and sgp130 and anthropomorphic characteristics, plasma markers of metabolic disease or liver pathology, adjusting for covariates of liver disease such as age, sex, BMI and diabetes.

Results: In patients with NASH, plasma IL-6 and sgp130 strongly correlated with liver stiffness, which for sgp130, was independent of age, sex, BMI, and chronic disease (diabetes, hyperlipidemia, hypertension or history of HCC). Plasma sgp130 was the strongest predictor of liver stiffness compared to commonly used biomarkers and predictive algorithms. Plasma sIL-6R correlated with liver volume independent of age, sex, and BMI. In stepwise forward regression analysis, plasma sgp130 followed by NAFLD fibrosis score and plasma globulin, predicted up to $74 \%$ of liver stiffness with/without adjustment for sex. In morbidly obese subjects, circulating IL6 correlated with hepatocellular ballooning and sgp130 correlated with advanced liver fibrosis.

Conclusions: Circulating sgp130 could represent a robust biomarker of active NASH and may be used alone or in combination with other biomarkers as a non-invasive measure of liver disease severity. 
medRxiv preprint doi: https://doi.org/10.1101/2022.01.10.22268968; this version posted January 11, 2022. The copyright holder for this preprint (which was not certified by peer review) is the author/funder, who has granted medRxiv a license to display the preprint in perpetuity. It is made available under a CC-BY-NC-ND 4.0 International license .

\section{INTRODUCTION}

Nonalcoholic fatty liver disease (NAFLD) is rapidly increasing worldwide, with global prevalence of the disease reaching approximately 25\% [1-3]. NAFLD is a multistep, progressive disease that begins with simple steatosis that can evolve to non-alcoholic steatohepatitis (NASH) characterized by hepatocellular ballooning, lobular inflammation, and a range of fibrosis. Simple steatosis is relatively benign; however, NASH can progress to cirrhosis and/or hepatocellular carcinoma (HCC) [4]. NASH is now considered the second most common indication for liver transplantation and HCC in Canada [5]. Each step of the NAFLD spectrum adversely affects the health and survival of patients. A current challenge is to accurately detect early stages of advancing liver disease, as resulting fibrosis is a primary predictor of liver related morbidity and mortality in NAFLD [6]. However, the transition of simple steatosis to NASH is generally asymptomatic, limiting early diagnosis of NASH and risk stratification.

Liver biopsy and radiological assessment of liver pathology are accurate diagnostic tools; however, these are invasive, expensive, and not widely available. Initial diagnoses often use liver risk scores calculated from age, body mass index (BMI), diabetes status, and plasma liver enzymes (alanine and aspartate aminotransferases, ALT and AST) to predict NAFLD progression and severity. However, recent evidence suggests that BMI poorly correlates with NAFLD severity [7] and as high as $80 \%$ of subjects with NAFLD and $19 \%$ of subjects with biopsy-proven NASH have normal liver enzyme levels [8-11]. Thus, relying on obesity and increased liver enzymes to screen for NAFLD may lead to many patients remaining undiagnosed or unaware of the severity of liver damage. The transition from simple steatosis to NASH is an important stage of the disease that correlates strongly with poor prognosis. Currently, there are no sensitive biomarkers of the early, inflammatory stages of NASH. Identification of non-invasive, reliable biomarkers of hepatic inflammation and fibrosis, especially at early stages (F1 and F2), will facilitate diagnosis and possibly increase success rates of emerging interventions and treatment strategies.

Interleukin-6 (IL-6) is an inflammatory cytokine released from liver and other organs in subjects with metabolic disease [12-16]. It has both pro- and anti-inflammatory properties and may play a role in the progression of NAFL to NASH [17, 18], cirrhosis [19] and liver cancer [20]. IL- 
6 signaling involves either activation of a membrane-bound receptor (classical) or formation of a signaling complex with a soluble IL-6 receptor (sIL-6R) found in circulation (trans-signaling). Circulating IL-6/sIL-6R complexes bind their membrane-bound co-receptor, glycoprotein 130 (gp130), on the surface of cells to activate signaling in tissues that do not have an IL-6 receptor. A soluble, secreted form of this co-receptor, sgp130, also circulates and can inhibit trans-signaling by sequestering the IL-6/sIL-6R complex [21]. There is some evidence linking increased IL-6 trans-signaling to metabolic diseases $[15,22]$, as well as to alcohol- and infection-induced chronic liver disease [23].

Given the involvement of IL-6 signaling at all stages of NAFLD progression, we hypothesized that circulating mediators of the IL- 6 trans-signaling pathway may predict NAFLD severity in populations with NASH and/or morbid obesity. In this study, we investigated relationships between circulating IL-6, sIL-6R and sgp130, and liver pathology associated with metabolic syndrome in two human cohorts. 
medRxiv preprint doi: https://doi.org/10.1101/2022.01.10.22268968; this version posted January 11, 2022. The copyright holder for this preprint (which was not certified by peer review) is the author/funder, who has granted medRxiv a license to display the preprint in perpetuity.

It is made available under a CC-BY-NC-ND 4.0 International license .

\section{STUDY POPULATION AND METHODS}

\section{Patients with NASH}

Participants were selected from a registry of 493 patients with available liver biopsies collected under ethical approval (IRB: \#15.147) at Centre hospitalier de l'Université de Montréal that was initiated in February 2016. NASH was previously confirmed by liver biopsies performed according to the clinical standard of care using $16-\mathrm{G}$ or $18-\mathrm{G}$ core needles. Hematoxylin and eosin (H\&E) slides were scored by liver pathologists, with fibrosis stage, inflammation grade, and steatosis grade assessed according to the NASH Clinical Research Network (NASH CRN) histological scoring system [24].

All participants provided written, informed consent allowing preservation and subsequent use of their data. To be included in this study (IRB \# 17.031), subjects were aged 18 years and older, diagnosed with NASH or with $\mathrm{HCC}$ on a NASH background, able to undergo magnetic resonance imaging (MRI) without administration of a contrast agent and to understand instructions in either French or English. Subjects were excluded if they: had high alcohol consumption ( $>10$ drinks/week for women and >15 for men); had liver disease other than NASH; were taking medications associated with steatosis (e.g. amiodarone, valproate, tamoxifen, methotrexate or corticosteroids); physically unable to fit in the MRI machine; had contraindications to MRI; or were pregnant or wished to be pregnant during the study-year.

Of the 493 patients, 133 patients were eligible for this study, of whom 89 were diagnosed with NASH and 44 with NASH and a previous history of HCC. Between May 2018 and June 2019, which represents six to twelve months after the liver biopsies and diagnosis with NASH the 133 patients were invited back for an MRI/MRE scan to assess liver fat fraction, volume and liver stiffness. Among these, 49 subjects with NASH alone and 34 with HCC and NASH did not participate in the study for the following reasons: refusal $(n=40)$, unreachable $(n=25)$, cancellation $(n=8)$, distance to the hospital $(n=8)$, language issues $(n=1)$ or other reasons (comorbidities including amputations) $(n=1)$. Thus, this prospective analysis including 40 patients with NASH ( 28 women, 22 men) and 10 patients with NASH and a history of HCC (4 women and 6 men) from the original registry of 493 patients. All patients $(n=50)$ signed a consent form to be included in this study, approved by the Centre hospitalier de l'Université de Montréal human ethics committee 
(IRB \#17.031). A flowchart of inclusion/exclusion criteria used is shown in Supplementary Figure 1.

MRI/MRE examinations were performed using a 3.0 T clinical scanner (Skyra; Siemens Healthineers, Mountain View, California). Proton density fat fraction (PDFF), liver volume (voxels, $\mathrm{cm}^{3}$ ), and liver stiffness $(\mathrm{Pa})$ were measured as quantitative biomarkers of liver fat, volume and fibrosis, respectively. Average PDFF values for the entire liver volume were obtained using the LiverLab package (Magnetom Aera, Software version VE11C, Siemens Healthcare $\mathrm{GmbH}$, Erlangen, Germany). Liver stiffness measurements by MRE were performed according to previously described methods [25]. Fasting plasma samples were collected on the day of the $\mathrm{MRI} / \mathrm{MRE}$ and stored at $-80^{\circ} \mathrm{C}$ until measurement of plasma IL-6 parameters and other biomarkers for calculation of the liver disease scores.

\section{Calculation of fasting NAFLD fibrosis score, FIB-4 index and APRI score}

The following equations were used to calculate liver scores in the NASH population:

NAFLD fibrosis score $=-1.675+[0.037 \mathrm{x}$ age $($ years $)]+\left[0.094 \times \mathrm{BMI}\left(\mathrm{kg} / \mathrm{m}^{2}\right)\right]+[1.13 \times$ impaired fasting glucose/diabetes $(\mathrm{yes}=1, \mathrm{no}=0)]+[0.99 \times \mathrm{AST} / \mathrm{ALT}$ ratio $]-[0.013 \times$ platelet count $(\times$ $\left.\left.10^{9} / \mathrm{L}\right)\right]-[0.66 \times$ albumin $(\mathrm{g} / \mathrm{dl})][26]$.

Fibrosis-4 $\left(\right.$ FIB-4) index $=[$ Age $($ years $)] \times[$ AST $(\mathrm{U} / \mathrm{L})] /\left[\right.$ platelet count $\left(10^{9} / \mathrm{L}\right) \times$ sqrt $($ ALT $)$ $(\mathrm{U} / \mathrm{L})][27]$.

AST to platelet count ratio index (APRI): $[\mathrm{AST}(\mathrm{IU} / \mathrm{L}) / 40 \mathrm{IU} / \mathrm{L}] /\left[\right.$ platelet $\left.\left.\operatorname{count}\left(\times 10^{9} / \mathrm{L}\right)\right]\right] \times 100$ [28].

\section{Patients with morbid obesity}

Plasma samples and matching liver biopsies were obtained from the Biobank of the Institut universitaire de cardiologie et de pneumologie de Québec - Université Laval in compliance with Institutional Review Board-approved management policies initiated in 2002 and still ongoing. Adult men and women (18 years and older) were selected from a registry of 4,781 patients undergoing bariatric surgery. Exclusion criteria were: having high alcohol consumption $(>10$ drinks/week for women and $>15$ for men); or having liver disease other than NASH (e.g. autoimmune hepatitis, Wilson disease, hemochromatosis or HBV, HCV or human 
immunodeficiency viruses). Thus, this retrospective analysis included a subpopulation of 245 subjects (123 men, 122 women) selected based on availability of serum and histological scoring data.

Random blood samples were collected on the night before bariatric surgery and stored immediately at $-80^{\circ} \mathrm{C}$ until time of analysis. Liver biopsy samples were collected at the time of surgery under ethical approval (IRB: \#1142). Sampling procedure and position were standardized among all surgeons. Liver samples were obtained by incisional biopsy of the left lobe and were not cauterized. Grading and staging of histological liver sections were performed using the protocol of Brunt et al [29] by pathologists blinded to the study objectives. Bedossa algorithm [30] was used to diagnose NASH, using liver biopsy histological scores for hepatocellular ballooning stage (0-2), lobular inflammation (0-2), steatosis grade (G0-G3), activity score (A0-A4) and fibrosis stage (F0-F4). These were also used to calculate NAFLD activity (NAS) and steatosis, activity and fibrosis (SAF) scores [30]. All participants provided written, informed consent allowing preservation and subsequent use of their plasma samples and data.

\section{Measurements of plasma IL-6, sIL-6R, sgp130, Cytokeratin-18 and Alanine aminotransferase (ALT)}

Commercial ELISA kits were used to measure plasma concentrations of IL-6, sIL-6R and sgp130 (R\&D systems, Human Quantikine ELISA kits, D6050, DR600, and DGP00 respectively) and Cytokeratin-18 (Peviva, M30 Apoptosense ELISA, 10011). For sgp130 and sIL-6R, samples were diluted 1:100, while for IL-6 and Cytokeratin-18, undiluted samples were used. ALT was measured in morbid obesity patients using a kit (SGPT liquid ALT reagent set, Pointe scientific A7526). All assays performed according to manufacturer's instructions and quality controls/standard provided with kits were included. All samples were assigned a unique alphanumerical identifier that did not correspond to any physiological parameter. The person performing the assays was blinded to the results of other assays during data collection.

\section{Statistical analysis}

Data in Table 1 and Table 5 are presented as mean \pm SD for continuous variables and as the number of subjects $(n)$ and percentage (\%) within the subpopulation for categorial variables. 
Normality was evaluated using a Kolmogrov-Smirnov test. When normality failed, data was $\log$ transformed $\left(\log _{10}\right)$. Outlier and influencer points were identified using SPSS. One subject in the NASH cohort was a strong influencer for plasma IL-6 and sIL-6R in all analysis. Thus, this subject was excluded from analyses. Unpaired t-test, one-way ANOVA and Pearson correlation were used to analyze parametric or $\log _{10}$ transformed data. Given the variability of some continuous data in tables 1 and 5, sensitivity analysis was performed with the use of a nonparametric Mann-Whitney $U$ test for intergroup differences to validate significant findings. For categorical variables, chisquare test was used for count $>5$ in each cell, otherwise Fisher's exact test was used.

Clinical endpoints used were liver fat fraction, volume and stiffness for the NASH cohort, and liver steatosis grade, activity score and fibrosis stage for patients with morbid obesity. To assess relationships between circulating IL-6, sIL-6R and sgp130 and these endpoints, stepwise linear regression analysis was used to predict measurements of liver disease severity using $\log _{10}$ [plasma IL-6], $\log _{10}$ [plasma sIL-6R] and $\log _{10}$ [plasma sgp130] as independent variables with adjustment for age, sex, and BMI and diabetes, hyperlipidemia, hypertension or previous HCC history for the NASH cohort. For the patients with morbid obesity cohort, $\log _{10}$ [plasma IL-6], sIL6R and sgp130 were used as independent variables with adjustment for age, sex, BMI and diabetes. For categorical variables (NASH cohort: liver steatosis stage, activity score and fibrosis stage. Patients with morbid obesity: liver steatosis stage, activity score and fibrosis stage, Bedossa NASH diagnosis, NAS and SAF score), univariate analysis was used with adjustment for age, sex, BMI and diabetes. Data was analyzed using IBM SPSS (Version 27) and GraphPad Prism (Version 8) and significance was set at $P<0.05$. 
medRxiv preprint doi: https://doi.org/10.1101/2022.01.10.22268968; this version posted January 11, 2022. The copyright holder for this preprint (which was not certified by peer review) is the author/funder, who has granted medRxiv a license to display the preprint in perpetuity. It is made available under a CC-BY-NC-ND 4.0 International license .

\section{RESULTS}

\section{Characteristics of patients with NASH}

Anthropometric, metabolic, and clinical characteristics of the patients with NASH (28 women and 21 men) are presented in Table 1. Among the total population, $44.9 \%$ of subjects had diabetes, $49.0 \%$ had obesity, 28.6\% had hyperlipidemia, 44.9\% had hypertension and 40.8\% consumed alcohol in moderation. Hepatic histological evaluation of the patients revealed that $75.0 \%$ had stage 2 steatosis, $70.0 \%$ had an activity score of 2 , and $87.5 \%$ had stage $1-2$ fibrosis at the time of the biopsy (Table 1). MRI/MRE measures of liver fat, volume and stiffness were affected by comorbidities in patients with NASH. Liver fat fraction was lower in patients with a previous history of HCC; liver volume was significantly higher in patients with diabetes and/or obesity; and liver stiffness was higher in patients with diabetes, obesity, hypertension and/or a previous history of HCC (Supplementary Figure 2A-R).

As presented in Table 1, plasma globulin, ALT, GGT, glycemia and HbAlc levels were higher than normal ranges in the Canadian population [31]. In line with expected sex differences, blood platelet count was lower, and plasma AST and GGT were higher, in men compared to women [31]. In healthy subjects, normal serum levels of plasma IL-6 are $<3 \mathrm{pg} / \mathrm{ml}[31,32]$ and average plasma concentrations are $35 \mathrm{ng} / \mathrm{ml}$ for sIL-6R and $217 \mathrm{ng} / \mathrm{ml}$ for sgp130 [32, 33]. In our cohort, average plasma IL-6 and spg130 were above those reported for healthy subjects, while average levels of sIL-6R were close to normal (Table 1). $\log _{10}$ [plasma IL-6] was significantly higher in NASH patients with diabetes, hypertension or previous history of HCC compared to NASH patients without these co-morbidities (Figure 1A, 1J, and 1P). $\log _{10}$ [plasma IL-6] also positively correlated with BMI (Supplementary Table 1), as previously reported [15, 16, 30, 31]. $\log _{10}$ [plasma sIL-6R] was higher in patients with diabetes (Figure 1B) and $\log _{10}$ [plasma sgp130] was higher in patients with hypertension or history of HCC (Figure 1L and 1R).

\section{Plasma sgp130 predicts the severity of liver stiffness independent of age, sex, adiposity, and comorbidities in patients with NASH}

Histological measures from liver biopsy (steatosis, active liver inflammation and liver fibrosis) are often used to diagnose NASH and define the range of disease severity. As shown in Table 1 and Supplementary Figure 3, all subjects without previous HCC history in this cohort 
medRxiv preprint doi: https://doi.org/10.1101/2022.01.10.22268968; this version posted January 11, 2022. The copyright holder for this preprint (which was not certified by peer review) is the author/funder, who has granted medRxiv a license to display the preprint in perpetuity. It is made available under a CC-BY-NC-ND 4.0 International license .

were in the early stages of NASH (F1-F2) at the time of biopsy. Six to twelve months after biopsies, MRE/MRI scans were performed, and fasting blood samples were collected for measurement of plasma IL-6-related parameters and other biomarkers. $\log _{10}$ [plasma IL-6], $\log _{10}$ [plasma sIL-6R] or $\log _{10}$ [plasma sgp130] were not significantly different between subjects with varying NASH severity assessed by histology (steatosis grade, activity score or fibrosis stage) (Supplementary Figure 3). This may be secondary to changes in NASH severity that could have occurred during the 6-12 months between the time of liver biopsy and MRE/MRI/blood collection. This possibility was supported by the fact that there was no correlation between liver histology scores and plasma ALT (Supplementary Figure 4A, 4B, 4C) or liver stiffness (Supplementary Figure 4D, 4E, 4F) measured at the time of the MRI/MRE scan. Thus, we focused our analysis to explore relationships between MRE/MRI measures of liver disease (liver fat fraction, volume and fibrosis/stiffness) and plasma levels of IL-6, sIL-6R and sgp130 and other biomarkers collected on the same day as the MRI/MRE.

In contrast to localized biopsy, liver volume and liver stiffness (resistance of the tissue to deformation) are both accurately measured over the entire liver by MRI/MRE [34]. Increased volume is influenced by a number of factors including fat content, inflammation, and/or edema, while increased stiffness is more indicative of increased inflammation and/or fibrosis [35]. Of the three components of the IL-6 pathway, $\log _{10}$ [plasma sgp130] was negatively correlated with liver fat fraction (Figure 2C) while $\log _{10}$ [plasma sIL-6R] was positively correlated with liver volume (Figure 2E). Moreover, both $\log _{10}$ [plasma IL-6] and $\log _{10}$ [plasma sgp130] positively correlated with liver stiffness (Figure 2G and 2I), with $\log _{10}$ [plasma sgp130] showing a strong correlation of $\mathrm{r}=0.77(\mathrm{p}<0.0001)$.

Stepwise forward regression analysis was performed to explore whether the association of components of the IL-6 pathway with MRE/MRI measures of liver disease were independent of age, sex, BMI, and the other comorbidities (diabetes, hyperlipidemia, hypertension, or previous HCC history). As presented in Table 2, adjustment for age, sex, BMI and any comorbidity eliminated associations of $\log _{10}$ [plasma IL-6] with all MRE/MRI measures of liver disease (liver fat, volume and stiffness). $\log _{10}$ [plasma sIL-6R] predicted liver volume independent of age, sex, BMI, and hyperlipidemia, hypertension or previous HCC history, but was influenced by diabetes. 
medRxiv preprint doi: https://doi.org/10.1101/2022.01.10.22268968; this version posted January 11, 2022. The copyright holder for this preprint (which was not certified by peer review) is the author/funder, who has granted medRxiv a license to display the preprint in perpetuity. It is made available under a CC-BY-NC-ND 4.0 International license .

On the other hand, $\log _{10}$ [plasma sgp130] predicted liver stiffness independent of age, sex, BMI and any comorbidity, including diabetes. (Table 2).

\section{Plasma sgp130 predicts the severity of liver stiffness better than currently used plasma biomarkers of liver disease or calculated liver risk scores in patients with NASH}

We also observed multiple correlations between the 3 plasma components of the IL-6 pathway with: metabolic risk factors (age, BMI, plasma glucose, glycated hemoglobin and lipids); common risk scores used to estimate severity of the liver disease (NAFLD fibrosis score, FIB-4 index and APRI score); as well as, individual plasma parameters used to estimate NASH risk/severity and calculate risk scores (hemoglobin, globulin, INR-PT, platelet count, ALT, AST, ALP, GGT and albumin) (Supplementary Table 1). Most notably, $\log _{10}$ [plasma IL-6] correlated well with common plasma biomarkers of liver disease including ALP, GGT, and albumin, and well as scores used to assess NAFLD severity (NAFLD and FIB-4). In contrast, $\log _{10}$ [plasma sIL6R] correlated strongly with markers of metabolic disease including glycaemia and triglycerides, as well as the liver damage marker GTT and the fibrosis risk scores. Log 10 [plasma sgp130] correlated very strongly with multiple markers of liver damage including platelet count, INR-PT, ALP, GGT, albumin and all fibrosis risk scores. These data are in line with IL-6 signaling being a major player in metabolic disease $[13,15,16,22,36,37]$ and suggest that different components of the pathway (i.e. ligand versus soluble receptors) may represent different aspects of the disease.

It has been shown that MRI/MRE based measurements of liver stiffness have good prognostic value to predict liver disease severity [38-40]. Consistent with this, multiple serum biomarkers of liver disease showed strong correlations with liver stiffness, including INR-PT, platelet count, ALP, GGT, albumin and CK-18 (Table 3). In addition, liver stiffness values correlated strongly with all fibrosis risk scores. However, $\log _{10}$ [plasma sgp130] had the strongest association with liver stiffness (Table 3) compared to all other metabolic risk factors, liver disease scores and individual biomarkers.

Metabolic diseases are influenced by sex and the liver is one of the most sexually dimorphic tissues [41]. Since NAFLD and NASH etiology and progression may be influenced by sex [4246], we next used stepwise linear regression analysis to the best predictors of liver fat, volume and 
medRxiv preprint doi: https://doi.org/10.1101/2022.01.10.22268968; this version posted January 11, 2022. The copyright holder for this preprint (which was not certified by peer review) is the author/funder, who has granted medRxiv a license to display the preprint in perpetuity. It is made available under a CC-BY-NC-ND 4.0 International license .

stiffness and determine whether sex influenced the strength of these associations. Independent parameters entered in the model were the 3 components of the IL-6 pathway (IL-6, sIL-6R and sgp130), plasma parameters related to liver disease (globulin, INR-PT, ALP, total bilirubin and GGT) and liver disease scores (NAFLD fibrosis score, FIB-4 index and APRI score). Age and BMI were not adjusted for in these regression models as they are used to calculate NAFLD fibrosis score and FIB-4 index.

As shown in Table 4, $\log _{10}$ [plasma ALP] and $\log _{10}$ [plasma GGT] were the primary predictors of $\log _{10}$ liver fat, predicting $26 \%$ of its intrasubject variation, followed by $\log _{10}$ [plasma spg130], which predicted an additional $9 \%$ of intrasubject variability. All other parameters were excluded and adjustment for sex had little effect on this model. $\log _{10}$ [plasma sgp130] was also retained in the regression model to predict $\log _{10}$ liver volume after $\log _{10}$ [plasma GGT], FIB-4 index and NAFLD fibrosis score; however, adjustment for sex excluded sgp130 from this regression model. On the other hand, $\log _{10}$ [plasma sgp130] was the primary predictor of liver stiffness, alone explaining $64 \%$ of its intrasubject variation, while NAFLD fibrosis score and $\log _{10}$ [plasma globulin] together explained an additional 9\% (Table 4). All other independent parameters were excluded and adjustment for sex had little effect on their ability to predict liver stiffness on this model (Table 4).

\section{Plasma sgp130 correlates with advanced liver disease in patients with morbid obesity}

Anthropometric, metabolic, and clinical characteristics of patients with morbid obesity are presented in Table 5. In line with published correlations between obesity and NAFLD [1], 98\% of these patients had hepatic steatosis. Among the population, 40.4\% had diabetes, $81.9 \%$ had NAFLD, and 16.5\% had NASH. However, despite extreme obesity (average BMI = 48), most were classified as NAFLD (not NASH) based on Bedossa scoring [30], with a high percentage of simple steatosis $(70.6 \%$, G0-G1), low activity score $(81.9 \%$, A0-A1), and low fibrosis stage $(59.6 \%$, F0F1) assessed from the liver biopsies. Histological evaluation showed generally low scores for immune cell infiltration and hepatocyte ballooning, with average NAFLD activity scores (NAS) falling between 2-3 (Table 5). Taken together, the overall degree of liver disease severity was low in this cohort of morbidly obese patients and indicated that this cohort likely had less active NASH than our first cohort at the time of liver biopsy. 
Subjects with diabetes had higher steatosis grade, activity score and fibrosis stage (Supplementary Figure 5A-C). There was no difference in BMI between subjects with different levels of disease severity based on steatosis grade, activity score or fibrosis stage (Supplementary Figure 5D-F). Average $\log _{10}$ [plasma ALT] concentration was higher only in subjects with G3 steatosis grade (Supplementary Figure 5G). Average $\log _{10}$ [plasma ALT] was increased in activity score A1 compared to A0 but did not increase further with rising activity severity (Supplementary Figure 5H). A similar trend for fibrosis was noted, with a significant increase in average $\log _{10}$ [plasma ALT] noted for F2 fibrosis compared to F0 (adjusting for age, sex, BMI and diabetes) (Supplementary Figure 5I), with no further increases noted with advancing fibrosis stage. Measurements for other serum biomarkers of liver damage were not available from this biobank.

Average plasma IL-6 in this study population was elevated, highly influenced by levels in women (Table 5). Plasma sIL-6R and spg130 in this population were also above levels reported in healthy subjects $[32,33]$ (Table 5). Similar to the NASH cohort, plasma IL-6, sIL-6R and sgp130 were higher in subjects with diabetes (Supplementary Figure 6A-C). We then examined plasma concentrations of IL-6, sIL-6R and sgp130 in relation to steatosis stage, activity score and fibrosis stage. After adjusting for age, sex, BMI and diabetes, none of the plasma concentrations of IL-6, sIL-6R and sgp130 were different among the different levels of steatosis grade or activity score. However, plasma sgp130 was higher in subjects with an F4 fibrosis stage compared to subjects with no fibrosis or lower fibrosis (stages 1-3) independent of age, sex, BMI and diabetes (Figure 3). Thus, in this cohort, our analysis suggested that increased sgp130 could detect advanced levels of fibrosis but was not particularly sensitive for this indicator of liver disease. 
medRxiv preprint doi: https://doi.org/10.1101/2022.01.10.22268968; this version posted January 11, 2022. The copyright holder for this preprint (which was not certified by peer review) is the author/funder, who has granted medRxiv a license to display the preprint in perpetuity. It is made available under a CC-BY-NC-ND 4.0 International license .

\section{DISCUSSION}

In this study we explored relationships between three components of the IL-6 signaling pathway (IL-6, sIL-6R and sgp130) and measures of liver disease severity evaluated by liver biopsy, MRE/MRI, plasma biomarkers and/or liver risk scores in two separate cohorts with diagnosed NASH or morbid obesity. We provide novel data showing that: 1) plasma concentrations of IL-6 signaling mediators are differentially increased in obesity, diabetes, hypertension and/or previous history of HCC in patients with NASH; 2) plasma sgp130 strongly predicts MRE/MRI measured liver stiffness independent of age, sex, BMI and any comorbidity (diabetes, hypertension, hyperlipidemia or history of HCC) in patients with NASH, performing superior to many other plasma biomarkers and liver risk scores; 3) plasma sgp130 is increased in advanced fibrosis independent of age, sex, BMI and diabetes in patients with morbid obesity; and finally, 4) plasma sIL-6R predicts MRE/MRI measures of liver volume, independent of age, sex and BMI.

In clinical practice, obesity, age, plasma ALT and diabetes status are used separately or in combination to predict advancing liver disease. Individual plasma or anthropometric parameters are rarely sufficient on their own to predict NAFLD, but their predicative power can increase significantly when used in combination. NAFLD fibrosis and BARD scores are widely used in clinical practice [26]. Fibrosis-4 (FIB-4) index, AST to platelet ratio (APRI) score and plasma cytokeratin-18 levels are used to exclude advanced fibrosis in NAFLD patients [27, 28]. Using stepwise linear regression analysis, we found plasma sgp130 performed better than other individual serum biomarkers and scores to predict liver stiffness in our NASH cohort across a wide range of disease severity. When combined with NAFLD fibrosis score and plasma globulin, the predicative power of the model increased. Thus, we propose that plasma sgp130 (alone or in combination with NAFLD fibrosis score) could be an effective, non-invasive method to predict the severity of liver disease in subjects with NASH.

Although we focus our attention on sgp130, we also found circulating sIL-6R to be associated with NAFLD pathology and liver disease severity. Our data suggest that sIL-6R may prove to be a useful, non-invasive biomarker of increased liver volume independent of age, sex and BMI. Interestingly, larger liver volume measured by MRI was recently associated with a 3- 
medRxiv preprint doi: https://doi.org/10.1101/2022.01.10.22268968; this version posted January 11, 2022. The copyright holder for this preprint (which was not certified by peer review) is the author/funder, who has granted medRxiv a license to display the preprint in perpetuity. It is made available under a CC-BY-NC-ND 4.0 International license .

fold increased risk of all-cause mortality [47]. Increased plasma IL-6 and sgp130 are also reported in $\mathrm{HBV} / \mathrm{HCV}$ infection or excessive alcohol consumption $[23,48,49]$. While high IL-6 is observed in subjects with HCC $[20,50]$, we report here for the first time that elevated sgp130 are also found in subjects with previous history of $\mathrm{HCC}$, but no detectable tumors. We cannot determine whether these high levels are linked to past liver damage or ongoing liver pathology linked to NASH. While further studies are needed, our data suggest that plasma levels of IL-6 and its trans-signaling components may be useful biomarkers of liver disease across a range of etiologies.

One limitation of our study is the use of different methods to quantify liver disease severity across the two populations. For the first cohort, we relied mainly on MRI and MRE analysis to assess severity of liver disease, while for the second cohort we used scoring data from liver biopsies. While liver biopsy data was available for our NASH cohort, analyses suggested that disease severity changed between the time of biopsy and the MRE/MRI/blood draw (6-12 months). Liver biopsy remains gold standard, but accumulating studies show that MRI/MRE also has high diagnostic accuracy for liver fibrosis, similar to biopsy, in subjects with NAFLD [38-40]. However, the two methods limited our ability to directly compare liver disease parameters such as steatosis grade, activity scores, and fibrosis stage between the cohorts.

Another limitation of our comparisons is that liver fibrosis and liver stiffness are not interchangeable. Liver fibrosis in biopsies is scored based on collagen staining, while MREdetermined liver stiffness is influenced by several biological and technical factors. Fibrosis and inflammation increase liver stiffness (although inflammation to a lesser extent), while stiffness is slightly decreased by steatosis [38-40]. This may explain discrepancies in sgp130 sensitivity to detect liver fibrosis (by collagen staining) across our cohorts. It is worth noting that our second cohort was composed of patients undergoing bariatric surgery, for which advanced NASH and cirrhosis were exclusion criteria for surgery. This limited the range of active liver disease in this population and led to low numbers for some activity and fibrosis stages. However, our data could also suggest that spg130 is a sensitive marker of active liver inflammation and damage, but not a biomarker of collagen deposition per se. Sgp130 is a component of an inflammatory signaling pathway, which could explain stronger correlation with liver stiffness versus collagen staining (a late consequence of damaging stimuli). In line with this theory, sgp130 was significantly increased 
only in late fibrosis stages determined by histology, while the strong linear correlation between plasma sgp130 and liver stiffness measured by MRI/MRE spanned across all stages of disease severity.

In conclusion, circulating components of the IL-6 signaling system may serve as sensitive biomarkers for NAFLD and NASH linked to metabolic disease. Importantly, the relationships between plasma sIL-6R and spg130 with metabolic liver disease severity are independent of sex, age and BMI in progressive NAFLD. These circulating biomarkers may represent powerful tools to help predict the severity of NASH linked to metabolic disease and may help to differentiate various stages of the disease over the early NAFLD to NASH transition. 


\section{FIGURE LEGENDS}

Figure 1. Plasma IL-6, sIL-6R and sgp130 levels in patients with NASH with or without diabetes (AC), obesity (D-F), hyperlipidemia (H-I), hypertension (J-L), alcohol consumption (M-O) and previous history of HCC (P-R). Data is presented as the distribution around the mean. Statistical significance was evaluated by un-paired t test. $n=28$ women (open circles) and $n=21$ men (closed circles).

Figure 2. Pearson correlations between plasma IL-6, sIL-6R and sgp130 with MRE/MRI measures of liver fat fraction (A, B, C), liver volume (D, E, F) and liver stiffness $(\mathrm{G}, \mathrm{H}, \mathrm{I})$ in patients with NASH. For liver fat fraction and liver volume, $n=28$ women (open circles) and $n=21$ men (closed circles). For liver stiffness, $n=27$ women (open circles) and $n=20$ men (closed circles).

Figure 3. Plasma concentrations of IL-6 (A, B, C), sIL-6R (D, E, F) and $\operatorname{sgp} 130$ (G, H, I) in patients with morbid obesity compared among liver biopsy measures of steatosis grade, activity score and fibrosis stage. Data presented for subjects with steatosis grade G0 $(n=5), \mathrm{G} 1(n=168)$, $\mathrm{G} 2(n=47), \mathrm{F} 3(n=41), \mathrm{F} 4(n=10)$, subjects with activity score A0 $(n=115), \mathrm{A} 1(n=84), \mathrm{A} 2(n=33)$, A3 ( $n=6), \mathrm{A} 4(n=5)$ and subjects with fibrosis stage F0 $(n=73), \mathrm{F} 1(n=73), \mathrm{F} 2(n=48), \mathrm{F} 3(n=41)$, F4 $(n=25)$. Analysis by 1-way ANOVA with multiple comparisons adjusted for age, sex, BMI and diabetes. 


\section{REFERENCES}

1. Younossi, Z.M., et al., Global epidemiology of nonalcoholic fatty liver disease-Metaanalytic assessment of prevalence, incidence, and outcomes. Hepatology, 2016. 64(1): p. 73-84.

2. $\quad$ Zhou, F., et al., Unexpected Rapid Increase in the Burden of NAFLD in China From 2008 to 2018: A Systematic Review and Meta-Analysis. Hepatology, 2019. 70(4): p. 1119-1133.

3. Li, J., et al., Prevalence, incidence, and outcome of non-alcoholic fatty liver disease in Asia, 1999-2019: a systematic review and meta-analysis. Lancet Gastroenterol Hepatol, 2019. 4(5): p. 389-398.

4. $\quad$ Paik, J.M., et al., Mortality Related to Nonalcoholic Fatty Liver Disease Is Increasing in the United States. Hepatol Commun, 2019. 3(11): p. 1459-1471.

5. Swain, M.G., et al., Burden of nonalcoholic fatty liver disease in Canada, 2019-2030: a modelling study. CMAJ Open, 2020. 8(2): p. E429-E436.

6. Younossi, Z.M., et al., Nonalcoholic steatofibrosis independently predicts mortality in nonalcoholic fatty liver disease. Hepatol Commun, 2017. 1(5): p. 421-428.

7. Eslam, M., et al., A new definition for metabolic dysfunction-associated fatty liver disease: An international expert consensus statement. J Hepatol, 2020. 73(1): p. 202-209.

8. Fracanzani, A.L., et al., Risk of severe liver disease in nonalcoholic fatty liver disease with normal aminotransferase levels: a role for insulin resistance and diabetes. Hepatology, 2008. 48(3): p. 792-8.

9. Uhanova, J.M., G; Premji, K; Chandok N.; Serial liver transaminases have no prognostic value in non-alcoholic fatty liver disease. Canadian Liver Journal, 2019. 2(1): p. 19-22.

10. Portillo-Sanchez, P., et al., High Prevalence of Nonalcoholic Fatty Liver Disease in Patients With Type 2 Diabetes Mellitus and Normal Plasma Aminotransferase Levels. J Clin Endocrinol Metab, 2015. 100(6): p. 2231-8.

11. Ma, X., et al., Proportion of NAFLD patients with normal ALT value in overall NAFLD patients: a systematic review and meta-analysis. BMC Gastroenterol, 2020. 20(1): p. 10.

12. Bastard, J.P., et al., Elevated levels of interleukin 6 are reduced in serum and subcutaneous adipose tissue of obese women after weight loss. J Clin Endocrinol Metab, 2000. 85(9): p. 3338-42.

13. Yeste, D., et al., Interleukin-6 in obese children and adolescents with and without glucose intolerance. Diabetes Care, 2007. 30(7): p. 1892-4.

14. Charles, B.A., et al., The roles of $I L-6, I L-10$, and $I L-1 R A$ in obesity and insulin resistance in African-Americans. J Clin Endocrinol Metab, 2011. 96(12): p. E2018-22.

15. Weiss, T.W., H. Arnesen, and I. Seljeflot, Components of the interleukin-6 transsignalling system are associated with the metabolic syndrome, endothelial dysfunction and arterial stiffness. Metabolism, 2013. 62(7): p. 1008-13.

16. Chen, H., et al., Increased levels of IL-6, sIL-6R, and sgp130 in the aqueous humor and serum of patients with diabetic retinopathy. Mol Vis, 2016. 22: p. 1005-14.

17. Wieckowska, A., et al., Increased hepatic and circulating interleukin-6 levels in human nonalcoholic steatohepatitis. Am J Gastroenterol, 2008. 103(6): p. 1372-9.

18. Mohamed, K.A., et al., A study of Interleukin 6 as a predictive biomarker for development of nonalcholic steatohepatitis in patients with Nonalcholic fatty liver disease. QJM: An International Journal of Medicine, 2020. 113(Supplement_1). 
medRxiv preprint doi: https://doi.org/10.1101/2022.01.10.22268968; this version posted January 11, 2022. The copyright holder for this preprint (which was not certified by peer review) is the author/funder, who has granted medRxiv a license to display the preprint in perpetuity. It is made available under a CC-BY-NC-ND 4.0 International license .

19. Labenz, C., et al., Raised serum Interleukin-6 identifies patients with liver cirrhosis at high risk for overt hepatic encephalopathy. Aliment Pharmacol Ther, 2019. 50(10): p. 11121119.

20. Porta, C., et al., Circulating interleukin-6 as a tumor marker for hepatocellular carcinoma. Ann Oncol, 2008. 19(2): p. 353-8.

21. Schmidt-Arras, D. and S. Rose-John, IL-6 pathway in the liver: From physiopathology to therapy. J Hepatol, 2016. 64(6): p. 1403-15.

22. Nikolajuk, A., et al., Serum soluble glycoprotein 130 concentration is inversely related to insulin sensitivity in women with polycystic ovary syndrome. Diabetes, 2010. 59(4): p. 1026-9.

23. Lemmers, A., et al., An inhibitor of interleukin-6 trans-signalling, sgp130, contributes to impaired acute phase response in human chronic liver disease. Clin Exp Immunol, 2009. 156(3): p. 518-27.

24. Kleiner, D.E., et al., Design and validation of a histological scoring system for nonalcoholic fatty liver disease. Hepatology, 2005. 41(6): p. 1313-21.

25. Venkatesh, S.K., M. Yin, and R.L. Ehman, Magnetic resonance elastography of liver: technique, analysis, and clinical applications. J Magn Reson Imaging, 2013. 37(3): p. 54455.

26. Angulo, P., et al., The NAFLD fibrosis score: a noninvasive system that identifies liver fibrosis in patients with NAFLD. Hepatology, 2007. 45(4): p. 846-54.

27. Sterling, R.K., et al., Development of a simple noninvasive index to predict significant fibrosis in patients with HIV/HCV coinfection. Hepatology, 2006. 43(6): p. 1317-25.

28. Wai, C.T., et al., A simple noninvasive index can predict both significant fibrosis and cirrhosis in patients with chronic hepatitis $C$. Hepatology, 2003. 38(2): p. 518-26.

29. Brunt, E.M., et al., Nonalcoholic steatohepatitis: a proposal for grading and staging the histological lesions. Am J Gastroenterol, 1999. 94(9): p. 2467-74.

30. Bedossa, P., et al., Histopathological algorithm and scoring system for evaluation of liver lesions in morbidly obese patients. Hepatology, 2012. 56(5): p. 1751-9.

31. Reference Values for Biochemical Tests - Centre hospitalier de l'Université de Montréal. [Accessed December 2021]; Available from: https://www.chumontreal.qc.ca/sites/default/files/inlinefiles/180710_Valeurs_reference_Biochimie-CHUM_2018-05-08.pdf.

32. Nikolaus, S., et al., Evaluation of interleukin-6 and its soluble receptor components sIL$6 R$ and sgp130 as markers of inflammation in inflammatory bowel diseases. Int $\mathrm{J}$ Colorectal Dis, 2018. 33(7): p. 927-936.

33. Padberg, F., et al., CSF and serum levels of soluble interleukin-6 receptors (sIL-6R and sgp130), but not of interleukin-6 are altered in multiple sclerosis. J Neuroimmunol, 1999. 99(2): p. 218-23.

34. Tang, A., et al., Ultrasound Elastography and MR Elastography for Assessing Liver Fibrosis: Part 1, Principles and Techniques. American Journal of Roentgenology, 2015. 205(1): p. 22-32.

35. Lefebvre, T., et al., Prospective comparison of transient, point shear wave, and magnetic resonance elastography for staging liver fibrosis. Eur Radiol, 2019. 29(12): p. 6477-6488.

36. Zuliani, G., et al., Plasma soluble gp130 levels are increased in older subjects with metabolic syndrome. The role of insulin resistance. Atherosclerosis, 2010. 213(1): p. 31924. 
medRxiv preprint doi: https://doi.org/10.1101/2022.01.10.22268968; this version posted January 11, 2022. The copyright holder for this preprint (which was not certified by peer review) is the author/funder, who has granted medRxiv a license to display the preprint in perpetuity. It is made available under a CC-BY-NC-ND 4.0 International license .

37. Bowker, N., et al., Meta-analysis investigating the role of interleukin-6 mediated inflammation in type 2 diabetes. EBioMedicine, 2020. 61: p. 103062.

38. Costa-Silva, L., et al., MR elastography is effective for the non-invasive evaluation of fibrosis and necroinflammatory activity in patients with nonalcoholic fatty liver disease. Eur J Radiol, 2018. 98: p. 82-89.

39. Chen, J., et al., Diagnostic Performance of MR Elastography and Vibration-controlled Transient Elastography in the Detection of Hepatic Fibrosis in Patients with Severe to Morbid Obesity. Radiology, 2017. 283(2): p. 418-428.

40. Park, C.C., et al., Magnetic Resonance Elastography vs Transient Elastography in Detection of Fibrosis and Noninvasive Measurement of Steatosis in Patients With BiopsyProven Nonalcoholic Fatty Liver Disease. Gastroenterology, 2017. 152(3): p. 598-607 e2.

41. Roy, A.K. and B. Chatterjee, Sexual dimorphism in the liver. Annu Rev Physiol, 1983. 45: p. 37-50.

42. Li, Z., et al., Prevalence of nonalcoholic fatty liver disease in mainland of China: a metaanalysis of published studies. J Gastroenterol Hepatol, 2014. 29(1): p. 42-51.

43. van den Berg, E.H., et al., Prevalence and determinants of non-alcoholic fatty liver disease in lifelines: A large Dutch population cohort. PLoS One, 2017. 12(2): p. e0171502.

44. Long, M.T., et al., A simple clinical model predicts incident hepatic steatosis in a community-based cohort: The Framingham Heart Study. Liver Int, 2018. 38(8): p. 14951503.

45. Vilar-Gomez, E., et al., Fibrosis Severity as a Determinant of Cause-Specific Mortality in Patients With Advanced Nonalcoholic Fatty Liver Disease: A Multi-National Cohort Study. Gastroenterology, 2018. 155(2): p. 443-457 e17.

46. Yang, D., et al., Impact of sex on the survival of patients with hepatocellular carcinoma: $a$ Surveillance, Epidemiology, and End Results analysis. Cancer, 2014. 120(23): p. 3707-16.

47. Naeem, M., et al., Associations of liver volume and other markers of hepatic steatosis with all-cause mortality in the general population. Liver Int, 2021.

48. Sheng, T., et al., The Relationship Between Serum Interleukin-6 and the Recurrence of Hepatitis B Virus Related Hepatocellular Carcinoma after Curative Resection. Medicine (Baltimore), 2015. 94(24): p. e941.

49. Honda, M., et al., Human soluble IL-6 receptor: its detection and enhanced release by HIV infection. J Immunol, 1992. 148(7): p. 2175-80.

50. Shakiba, E., M. Ramezani, and M. Sadeghi, Evaluation of serum interleukin-6 levels in hepatocellular carcinoma patients: a systematic review and meta-analysis. Clin Exp Hepatol, 2018. 4(3): p. 182-190. 
medRxiv preprint doi: https://doi.org/10.1101/2022.01.10.22268968; this version posted January 11, 2022. The copyright holder for this preprint (which was not certified by peer review) is the author/funder, who has granted medRxiv a license to display the preprint in perpetuity.

Table 1. Anthropometric, metabolic and clinical characteristics of patients with NASH.

\begin{tabular}{|c|c|c|c|c|}
\hline & Total $(n=49)$ & Women $(n=28)$ & $\operatorname{Men}(n=21)$ & p value \\
\hline \multicolumn{5}{|l|}{ Baseline characteristics } \\
\hline Age (years) & $53.5 \pm 13.6$ & $53.5 \pm 13.1$ & $53.5 \pm 14.6$ & 0.988 \\
\hline Weight (kg) & $92.9 \pm 21.4$ & $89.9 \pm 22.2$ & $96.9 \pm 20.1$ & 0.260 \\
\hline Height (cm) & $170.5 \pm 8.9$ & $167.2 \pm 9.0$ & $175.0 \pm 6.6$ & 0.002 \\
\hline $\operatorname{BMI}\left(\mathrm{kg} / \mathrm{m}^{2}\right)$ & $31.7 \pm 5.4$ & $31.9 \pm 6.0$ & $31.4 \pm 4.7$ & 0.833 \\
\hline \multicolumn{5}{|l|}{ Clinical parameters } \\
\hline Diabetes $(n, \%)$ & $22,44.9$ & $13,46.4$ & $9,42.9$ & 0.804 \\
\hline Obesity $(n, \%)$ & $24,49.0$ & $12,42.9$ & $12,57.1$ & 0.322 \\
\hline Hyperlipidemia (n, \%) & $14,28.6$ & $8,28.6$ & $6,28.6$ & 1.000 \\
\hline Hypertension $(n, \%)$ & $22,44.9$ & $13,46.4$ & $9,42.9$ & 0.804 \\
\hline Alcohol consumption $(n, \%)$ & $20,40.8$ & $10,35.7$ & $10,47.6$ & 0.401 \\
\hline \multicolumn{5}{|l|}{ Diagnosis } \\
\hline NASH $(n, \%)$ & $39,79.6$ & $24,85.7$ & $15,71.4$ & 0.192 \\
\hline History of HCC $(n, \%)$ & $10,20.4$ & $4,14.3$ & $6,28.6$ & \\
\hline \multicolumn{5}{|l|}{ Medications } \\
\hline $\operatorname{Metformin}(n, \%)$ & $17,34.7$ & $11,39.3$ & $6,28.6$ & 0.436 \\
\hline Statins $(n, \%)$ & $12,24.5$ & $7,25.0$ & $5,23.8$ & 0.924 \\
\hline Corticosteroids $(n, \%)$ & $1,2.0$ & $1,3.6$ & $0,0.0$ & 1.000 \\
\hline Nifedipine $(n, \%)$ & $1,2.0$ & $1,3.6$ & $0,0.0$ & 1.000 \\
\hline Diltiazem $(n, \%)$ & $0,0.0$ & $0,0.0$ & $0,0.0$ & \\
\hline Insulin $(n, \%)$ & $2,4.1$ & $0,0.0$ & $2,9.5$ & 0.179 \\
\hline Estrogen $(n, \%)$ & $0,0.0$ & $0,0.0$ & $0,0.0$ & \\
\hline Methotrexate $(n, \%)$ & $0,0.0$ & $0,0.0$ & $0,0.0$ & \\
\hline Tamoxifen $(n, \%)$ & $0,0.0$ & $0,0.0$ & $0,0.0$ & \\
\hline
\end{tabular}

\section{Liver biopsy histological data}

Steatosis stage $(n, \%)^{\mathrm{a}}$

\section{0}

1

2

$\operatorname{Activity}(n, \%)^{\mathrm{a}}$

$\begin{array}{lll}1,2.5 & 0,0.0 & 1,6.7 \\ 9,22.5 & 7,28.0 & 2,13.3 \\ 30,75.0 & 18,72.0 & 12,80.0\end{array}$

\section{0}

1

2

3

Fibrosis stage $(n, \%)^{\mathrm{a}}$

0

1

2

3

4

$\begin{array}{lll}1,2.5 & 0,0.0 & 1,6.7 \\ 9,22.5 & 6,24.0 & 3,20.0 \\ 28,70.0 & 18,72.0 & 10,66.7 \\ 2,5.0 & 1,4.0 & 1,6.7\end{array}$

$\begin{array}{lll}1,2.5 & 1,4.0 & 0,0.0 \\ 14,35.0 & 10,40.0 & 4,26.7 \\ 21,52.5 & 13,52.0 & 8,53.3 \\ 3,7.5 & 0,0.0 & 3,20.0 \\ 1,2.5 & 1,4.0 & 0,0.0\end{array}$

\section{MRI/MRE data}

Liver fat fraction (\%)

Liver stiffness $(\mathrm{Pa})^{\mathrm{b}}$

$\begin{array}{llll}12.3 \pm 8.9 & 11.7 \pm 9.2 & 13.0 \pm 8.7 & 0.609 \\ 3338.5 \pm 1798.2 & 3014.8 \pm 1624.1 & 3775.6 \pm 1967.0 & 0.154 \\ 2019.5 \pm 679.9 & 1958.2 \pm 732.3 & 2101.3 \pm 611.0 & 0.472\end{array}$

\section{Fasting plasma parameters}

Hemoglobin $(\mathrm{mg} / \mathrm{dL})^{\mathrm{b}}$

Globulin $(\mathrm{g} / \mathrm{dL})^{\mathrm{b}}$

INR-PT ${ }^{\mathrm{C}}$

\section{$139.3 \pm 14.5$}

$6.2 \pm 2.3$

$1.0 \pm 0.1$
$136.1 \pm 14.3$

$6.6 \pm 2.5$

$0.9 \pm 0.1$
$143.6 \pm 14.0$

0.082

$5.7 \pm 2.0$

0.213

$1.0 \pm 0.1$
0.144 
medRxiv preprint doi: https://doi.org/10.1101/2022.01.10.22268968; this version posted January 11, 2022. The copyright holder for this preprint (which was not certified by peer review) is the author/funder, who has granted medRxiv a license to display the preprint in perpetuity.

\begin{tabular}{|c|c|c|c|c|}
\hline Platelet count $\left(* 10^{9} / \mathrm{L}\right)^{\mathrm{b}}{ }^{\mathrm{t} \mathrm{I}}$ & $\begin{array}{l}\text { de available und } \\
198.1 \pm 79.8\end{array}$ & $219.0 \pm 84.1$ & $\begin{array}{l}\text { ernational license } \\
170.0 \pm 65.5\end{array}$ & 0.036 \\
\hline $\operatorname{AST}(\mathrm{U} / \mathrm{L})^{\mathrm{b}}$ & $34.0 \pm 16.3$ & $29.7 \pm 13.6$ & $39.9 \pm 18.2$ & $\mathbf{0 . 0 3 4}$ \\
\hline $\operatorname{ALT}(\mathrm{IU} / \mathrm{L})^{\mathrm{b}}$ & $49.8 \pm 39.8$ & $40.6 \pm 22.5$ & $62.2 \pm 53.4$ & 0.066 \\
\hline $\operatorname{ALP}(\mathrm{IU} / \mathrm{L})^{\mathrm{b}}$ & $81.3 \pm 34.7$ & $80.9 \pm 32.4$ & $82.0 \pm 38.4$ & 0.919 \\
\hline Total bilirubin $(\mu \mathrm{mol} / \mathrm{L})^{\mathrm{b}}$ & $13.5 \pm 8.3$ & $13.4 \pm 10.2$ & $13.6 \pm 4.8$ & 0.926 \\
\hline $\operatorname{GGT}(\mathrm{U} / \mathrm{L})^{\mathrm{d}}$ & $64.7 \pm 63.6$ & $46.1 \pm 43.9$ & $91.1 \pm 78.0$ & 0.017 \\
\hline $\operatorname{Albumin}(\mathrm{g} / \mathrm{L})^{\mathrm{b}}$ & $42.6 \pm 4.7$ & $42.3 \pm 4.2$ & $43.1 \pm 5.3$ & 0.607 \\
\hline Glycaemia $(\mathrm{mmol} / \mathrm{L})^{\mathrm{e}}$ & $6.6 \pm 2.9$ & $6.6 \pm 2.7$ & $6.6 \pm 3.2$ & 0.966 \\
\hline $\mathrm{Hb} 1 \mathrm{Ac}(\%)^{\mathrm{c}}$ & $6.1 \pm 1.2$ & $6.1 \pm 1.0$ & $6.2 \pm 1.4$ & 0.809 \\
\hline Cholesterol $(\mathrm{mmol} / \mathrm{L})^{\mathrm{f}}$ & $4.4 \pm 1.1$ & $4.6 \pm 1.0$ & $4.1 \pm 1.1$ & 0.189 \\
\hline HDL-c $(\mathrm{mmol} / \mathrm{L})^{\mathrm{f}}$ & $1.1 \pm 0.2$ & $1.2 \pm 0.3$ & $1.1 \pm 0.2$ & 0.147 \\
\hline LDL-c $\left(\mathrm{mmol} / \mathrm{L}^{\mathrm{g}}\right.$ & $2.5 \pm 0.9$ & $2.7 \pm 0.9$ & $2.3 \pm 0.9$ & 0.175 \\
\hline Triglyceride $(\mathrm{mmol} / \mathrm{L})^{\mathrm{f}}$ & $1.9 \pm 1.2$ & $1.8 \pm 0.9$ & $2.0 \pm 1.5$ & 0.572 \\
\hline CK-18 (U/L) & $279.3 \pm 304.5$ & $189.2 \pm 166.2$ & $399.3 \pm 398.3$ & 0.015 \\
\hline
\end{tabular}

\begin{tabular}{lllll}
\hline Calculated liver risk scores & & & & \\
NAFLD fibrosis score $^{\mathrm{d}}$ & $-0.6 \pm 1.7$ & $-0.8 \pm 1.5$ & $-0.4 \pm 1.9$ & 0.440 \\
FIB-4 index $^{\mathrm{d}}$ & $2.1 \pm 2.1$ & $1.7 \pm 1.7$ & $2.6 \pm 2.5$ & 0.164 \\
APRI score $^{\mathrm{d}}$ & $0.6 \pm 0.4$ & $0.4 \pm 0.4$ & $0.8 \pm 0.5$ & $\mathbf{0 . 0 1 6}$ \\
& & & & \\
\hline Plasma components of the IL-6 pathway & & & \\
IL-6 $(\mathrm{pg} / \mathrm{ml})$ & $7.2 \pm 7.9$ & $8.3 \pm 8.9$ & $5.8 \pm 6.3$ & 0.271 \\
sIL-6R (ng/ml) & $38.7 \pm 12.0$ & $38.6 \pm 9.9$ & $39.0 \pm 14.6$ & 0.916 \\
Sgp130 $(\mathrm{ng} / \mathrm{ml})$ & $344.8 \pm 96.3$ & $341.4 \pm 104.5$ & $349.4 \pm 86.4$ & 0.776 \\
\hline
\end{tabular}

Data is presented as means $\pm \mathrm{SD}$ for continuous data and as sample size $(n)$ and percent within the population (\%) for categorical data. $\mathrm{P}$ value for differences between men and women measured by unpaired t-test for continuous data and by Chi square or Fishers exact test for categorical data. Significant findings hold for continuous data with high variability when performing nonparametric sensitivity analysis.

$\mathrm{P}$ value for differences between men and women.

${ }^{\text {a }}$ for $n$ is 25 for women, 15 for men.

${ }^{\mathrm{b}}$ for $n$ is 27 for women, 20 for men,

${ }^{\mathrm{c}}$ for $n$ is 26 for women, 20 for men,

d for $n$ is 27 for women, 19 for men,

${ }^{\mathrm{e}}$ for $n$ is 25 for women, 20 for men,

${ }^{\mathrm{f}}$ for $n$ is 26 for women, 19 for men,

$\mathrm{g}$ for $n$ is 25 for women, 18 for men. 
medRxiv preprint doi: https://doi.org/10.1101/2022.01.10.22268968; this version posted January 11, 2022. The copyright holder for this preprint (which was not certified by peer review) is the author/funder, who has granted medRxiv a license to display the preprint in perpetuity.

It is made available under a CC-BY-NC-ND 4.0 International license .

Table 2. Prediction of liver fat fraction, liver volume and liver stiffness by plasma IL-6 related cytokines.

\begin{tabular}{|c|c|c|c|c|}
\hline Dependent variable & Steps & Independent variables & Adjusted R ${ }^{2}$ & p value \\
\hline \multirow[t]{5}{*}{$\log _{10}$ [Liver fat fraction] } & & Model 1 & 0.12 & 0.044 \\
\hline & & Model 2 & 0.13 & 0.040 \\
\hline & & Model 3 & 0.12 & 0.044 \\
\hline & & Model 4 & 0.32 & $<0.001$ \\
\hline & 1 & & & \\
\hline \multirow[t]{8}{*}{$\log _{10}[$ Liver volume] } & & Model 1 & 0.50 & $<0.001$ \\
\hline & 1 & & & \\
\hline & & Model 2 & 0.41 & $<0.001$ \\
\hline & 1 & $\log _{10}$ (Plasma sIL-6R) & 0.46 & $<0.001$ \\
\hline & & Model 3 & 0.42 & $<0.001$ \\
\hline & 1 & $\log _{10}$ (Plasma sIL-6R) & 0.47 & $<0.001$ \\
\hline & 1 & Model 4 & 0.45 & $<0.001$ \\
\hline & 2 & $\log _{10}$ (Plasma sIL-6R) & 0.52 & $<0.001$ \\
\hline \multirow[t]{8}{*}{$\log _{10}[\text { Liver stiffness }]^{\mathrm{a}}$} & & Model 1 & 0.45 & $<0.001$ \\
\hline & 1 & $\log _{10}($ Plasma sgp130) & 0.69 & $<0.001$ \\
\hline & & Model 2 & 0.42 & $<0.001$ \\
\hline & 1 & $\log _{10}$ (Plasma sgp130) & 0.69 & $<0.001$ \\
\hline & & Model 3 & 0.42 & $<0.001$ \\
\hline & 1 & $\log _{10}$ (Plasma sgp130) & 0.69 & $<0.001$ \\
\hline & & Model 4 & 0.49 & $<0.001$ \\
\hline & 1 & $\log _{10}$ (Plasma sgp130) & 0.69 & $<0.001$ \\
\hline
\end{tabular}

$n=49$. Independent variables used were $\log _{10}\left[\right.$ plasma IL-6], $\log _{10}\left[\right.$ plasma sIL-6R] and $\log _{10}$ [plasma sgp130]. Regression models were adjusted for Model 1 (age, sex, BMI, and diabetes), Model 2 (age, sex, BMI, and hyperlipidemia), Model 3 (age, sex, BMI, and hypertension), Model 4 (age, sex, BMI, and hepatocellular carcinoma). a, $n=47$ 
medRxiv preprint doi: https://doi.org/10.1101/2022.01.10.22268968; this version posted January 11, 2022. The copyright holder for this preprint (which was not certified by peer review) is the author/funder, who has granted medRxiv a license to display the preprint in perpetuity.

Table 3. Correlations between common biomarkers of liver stiffness/fibrosis, liver risk scores

and components of the IL-6 pathway with MRI/MRE measures of liver stiffness, liver fat fraction and liver volume in NASH subjects.

$\log _{10}$

$\log _{10}$

$\log _{10}$

[Liver fat fraction]

[Liver volume]

[Liver stiffness] ${ }^{a}$

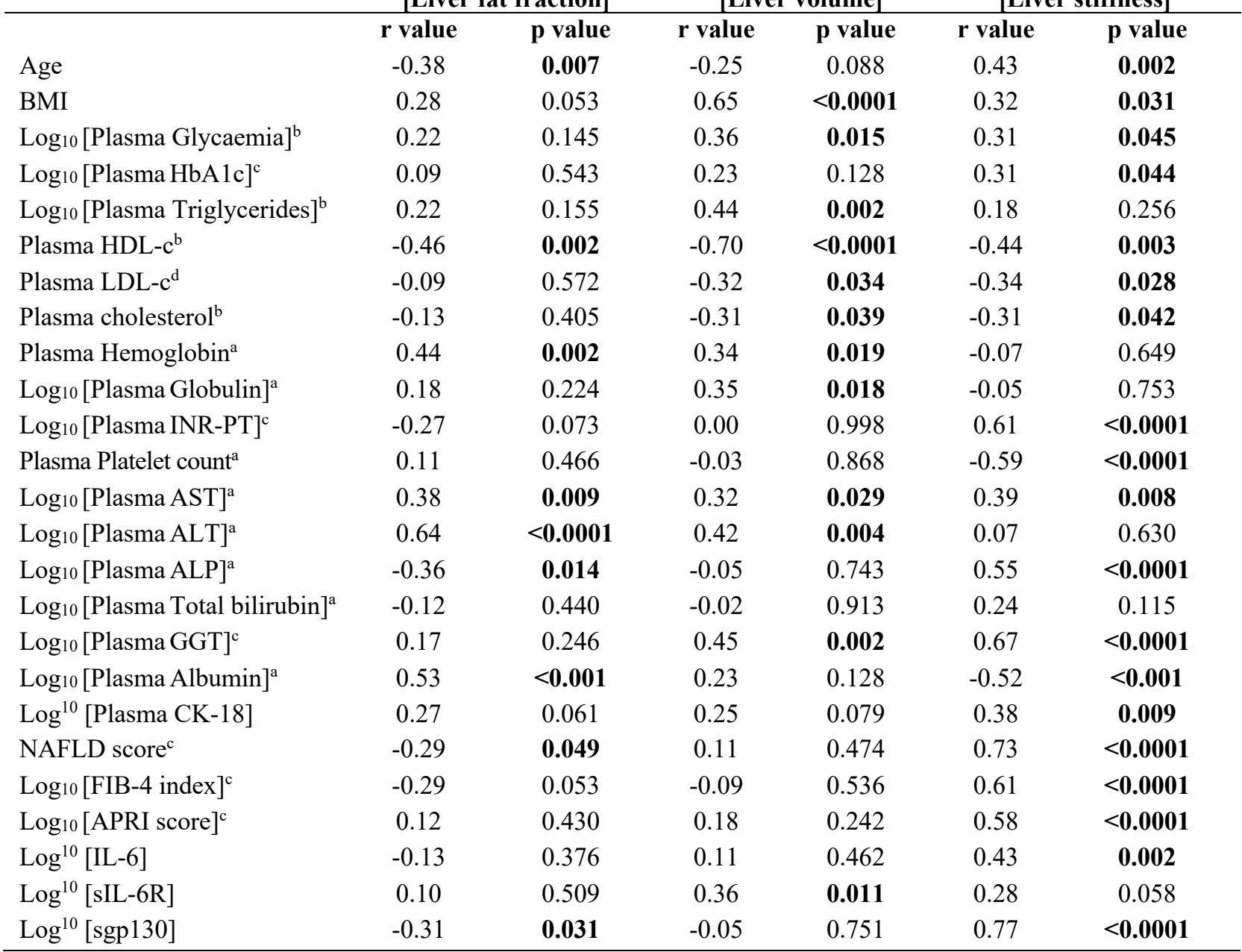

Statistical analysis was performed using Pearson's correlation. $n=49$ subjects ( $n=28$ women and $n=21$ men) except for ${ }^{\mathrm{a}}$ where $n=47,{ }^{\mathrm{b}}$ where $n=45,{ }^{\mathrm{c}}$ where $n=46$, and ${ }^{\mathrm{d}}$ where $n=43$. 
medRxiv preprint doi: https://doi.org/10.1101/2022.01.10.22268968; this version posted January 11, 2022. The copyright holder for this preprint (which was not certified by peer review) is the author/funder, who has granted medRxiv a license to display the preprint in perpetuity.

It is made available under a CC-BY-NC-ND 4.0 International license .

Table 4. Stepwise linear regression to predict liver fat fraction, liver volume and liver stiffness in NASH patients.

\begin{tabular}{|c|c|c|c|c|c|}
\hline Dependent variables & Steps & Independent variables & Constant coefficients & Adjusted $\mathbf{R}^{2}$ & p value \\
\hline \multirow[t]{4}{*}{$\log _{10}[$ Liver fat fraction] } & & & 5.091 & & \\
\hline & 1 & $\log _{10}[$ Plasma ALP $]$ & -0.707 & 0.14 & $\mathbf{0 . 0 3 8}$ \\
\hline & 2 & $\log _{10}[$ Plasma GGT] & 0.567 & 0.26 & $<0.001$ \\
\hline & 3 & $\log _{10}[$ Plasma sgp130] & -1.478 & 0.35 & 0.015 \\
\hline \multirow[t]{5}{*}{$\log _{10}$ [Liver volume] } & & & 3.995 & & \\
\hline & 1 & $\log _{10}$ [Plasma GGT] & 0.285 & 0.20 & $<0.001$ \\
\hline & 2 & $\log _{10}[$ Fib4 index $]$ & -0.282 & 0.36 & 0.003 \\
\hline & 3 & NAFLD score & 0.050 & 0.41 & 0.016 \\
\hline & 4 & $\log _{10}[$ Plasma sgp130] & -0.441 & 0.46 & 0.044 \\
\hline \multirow[t]{4}{*}{$\log _{10}[\text { Liver stiffness] }]^{a}$} & & & 0.503 & & \\
\hline & 1 & $\log _{10}[$ Plasma sgp130] & 1.112 & 0.64 & $<0.001$ \\
\hline & 2 & NAFLD score ${ }^{\mathrm{b}}$ & 0.044 & 0.69 & 0.001 \\
\hline & 3 & $\log _{10}[\text { Plasma globulin }]^{\mathrm{a}}$ & 0.261 & 0.73 & 0.012 \\
\hline \multirow[t]{5}{*}{$\log _{10}$ [Liver fat fraction] } & & & 5.104 & & \\
\hline & & Sex & -0.008 & 0.01 & 0.939 \\
\hline & 1 & $\log _{10}[\text { Plasma ALP }]^{a}$ & -0.708 & 0.15 & 0.040 \\
\hline & 2 & $\log _{10}\left[\right.$ Plasma GGT] ${ }^{\mathrm{b}}$ & 0.573 & 0.25 & 0.001 \\
\hline & 3 & $\log _{10}[$ Plasma sgp 130] & -1.485 & 0.33 & 0.017 \\
\hline \multirow[t]{5}{*}{$\log _{10}$ [Liver volume] } & & & 2.942 & & \\
\hline & & Sex & 0.013 & 0.002 & 0.730 \\
\hline & 1 & $\log _{10}[\text { Plasma GGT }]^{b}$ & 0.249 & 0.18 & $<0.001$ \\
\hline & 2 & $\log _{10}[\text { FIB-4 index }]^{b}$ & -0.342 & 0.34 & 0.001 \\
\hline & 3 & NAFLD score ${ }^{\mathrm{b}}$ & 0.046 & 0.40 & 0.037 \\
\hline \multirow[t]{5}{*}{$\log _{10}\left[_{\text {Liver stiffness }]^{\mathrm{a}}}\right.$} & & & 0.507 & & \\
\hline & & Sex & 0.045 & 0.01 & 0.162 \\
\hline & 1 & $\log _{10}$ [Plasma sgp130] & 1.097 & 0.64 & $<0.001$ \\
\hline & 2 & NAFLD score ${ }^{\mathrm{b}}$ & 0.044 & 0.69 & 0.001 \\
\hline & 3 & $\log _{10}\left[\right.$ Plasma globulin] ${ }^{\mathrm{a}}$ & 0.281 & 0.74 & 0.007 \\
\hline
\end{tabular}

Stepwise forward regressions analysis to predict liver fat fraction, liver volume and liver stiffness. Independent variables entered in the model were $\log _{10}$ [plasma IL-6], $\log _{10}$ [plasma sIL-6R], $\log _{10}$ [plasma sgp130], $\log _{10}$ [plasma globulin], $\log _{10}$ [plasma INR-PT], $\log _{10}$ [plasma ALP], $\log _{10}$ [plasma total bilirubin], $\log _{10}$ [plasma GGT], NAFLD fibrosis score, FIB4 index and APRI score. Regression models were repeated with adjustment for sex. $n=49$ subjects ( $n=28$ women and $n=21$ men) except for ${ }^{\mathrm{a}}$ where $n=47,{ }^{\mathrm{b}}$ where $n=46$. 
medRxiv preprint doi: https://doi.org/10.1101/2022.01.10.22268968; this version posted January 11, 2022. The copyright holder for this preprint (which was not certified by peer review) is the author/funder, who has granted medRxiv a license to display the preprint in perpetuity.

It is made available under a CC-BY-NC-ND 4.0 International license .

Table 5. Anthropometric, metabolic and clinical characteristics of patients with morbid obesity.

\begin{tabular}{lllll}
\hline & Total $(\boldsymbol{n}=\mathbf{2 4 5})$ & Women $(\boldsymbol{n}=\mathbf{1 2 2})$ & Men $(\boldsymbol{n}=\mathbf{1 2 3})$ & p value \\
\hline Baseline characteristics & & & & \\
Weight $(\mathrm{kg})$ & $135.8 \pm 26.4$ & $126.3 \pm 21.8$ & $145.5 \pm 26.8$ & $<\mathbf{0 . 0 0 0 1}$ \\
Height $(\mathrm{cm})$ & $168.1 \pm 9.3$ & $161.5 \pm 6.5$ & $174.6 \pm 6.7$ & $<\mathbf{0 . 0 0 0 1}$ \\
Age $($ years $)$ & $45.2 \pm 11.4$ & $44.0 \pm 11.1$ & $46.4 \pm 11.6$ & 0.094 \\
BMI $\left(\mathrm{kg} / \mathrm{m}^{2}\right)$ & $47.9 \pm 7.8$ & $48.3 \pm 7.3$ & $47.7 \pm 8.2$ & 0.621
\end{tabular}

\section{Clinical parameters}

Diabetes $(n, \%)$

$99,40.4$

$58,47.5$

$41,33.3$

0.023

\section{Bedossa algorithm for NASH}

$\begin{array}{llll}\text { No NAFLD }(n, \%) & 4,1.6 & 4,3.3 & 0,0.0 \\ \operatorname{NAFLD~}(n, \%) & 199,81.9 & 95,78.5 & 104,85.2 \\ \text { NASH }(n, \%) & 40,16.5 & 22,18.2 & 18,14.8\end{array}$

\section{Medications}

Hypertension $(n, \%)$

$111,45.3$

$44.0,36.1$

$67.0,54.5$

0.004

Diabetes $(n, \%)$

$51,20.8$

$25.0,20.5$

$26.0,21.1$

0.901

Dyslipidemia $(n, \%)$

$54,22.0$

23.0, 18.9

$31.0,25.2$

0.231

\section{Biochemical parameters}

$\begin{array}{lllll}\text { Glycaemia }(\mathrm{mmol} / \mathrm{L}) & 6.4 \pm 2.0 & 6.6 \pm 2.3 & 6.2 \pm 1.6 & 0.098 \\ \text { HbAlc }(\%)^{\mathrm{a}} & 6.0 \pm 1.1 & 6.1 \pm 1.1 & 6.0 \pm 1.1 & 0.542 \\ \text { Cholesterol (mmol/L) } & 4.5 \pm 1.0 & 4.6 \pm 0.9 & 4.5 \pm 1.0 & 0.572 \\ \text { HDL }(\mathrm{mmol} / \mathrm{L}) & 1.2 \pm 0.4 & 1.3 \pm 0.3 & 1.1 \pm 0.5 & \mathbf{0 . 0 0 3} \\ \text { LDL }(\mathrm{mmol} / \mathrm{L})^{\mathrm{b}} & 2.6 \pm 0.9 & 2.6 \pm 0.8 & 2.6 \pm 0.9 & 0.992 \\ \text { Triglyceride }(\mathrm{mmol} / \mathrm{L}) & 1.7 \pm 0.8 & 1.5 \pm 0.6 & 1.9 \pm 1.0 & \mathbf{0 . 0 0 4} \\ \text { ALT }(\mathrm{IU} / \mathrm{L}) & 33.9 \pm 22.4 & 33.4 \pm 28.6 & 34.4 \pm 14.0 & 0.730\end{array}$

\section{Liver biopsy histological data}

Liver Steatosis incidence $(n, \%)$

$242,98.8$

$119,97.5$

$123,100.0$

0.122

Liver Steatosis level ( $\%$ of liver)

$27.4 \pm 23.9$

$26.9 \pm 25.1$

$27.8 \pm 22.7$

0.768

Steatosis grade $(n, \%)$

$\begin{array}{llll}\text { G0 } & 5,2.0 & 5,4.1 & 0,0.0 \\ \text { G1 } & 168,68.6 & 78,63.9 & 90,73.2 \\ \text { G2 } & 47,19.2 & 26,21.3 & 21,17.1 \\ \text { G3 } & 25,10.2 & 13,10.7 & 12,9.8\end{array}$

$\operatorname{Activity}(n, \%)^{\mathrm{c}}$ 
medRxiv preprint doi: https://doi.org/10.1101/2022.01.10.22268968; this version posted January 11, 2022. The copyright holder for this preprint (which was not certified by peer review) is the author/funder, who has granted medRxiv a license to display the preprint in perpetuity. It is made available under a CC-BY-NC-ND 4.0 International license.

$\begin{array}{llll}\text { A0 } & 115,47.3 & 56,46.3 & 59,48.4 \\ \text { A1 } & 84,34.6 & 40,33.1 & 44,36.1 \\ \text { A2 } & 33,13.6 & 16,13.2 & 17,13.9 \\ \text { A3 } & 6,2.5 & 4,3.3 & 2,1.6 \\ \text { A4 } & 5,2.1 & 5,4.1 & 0,0.0\end{array}$

Fibrosis stage $(n, \%)$

$\begin{array}{llll}\text { F0 } & 73,29.8 & 30,24.6 & 43,35.0 \\ \text { F1 } & 73,29.8 & 30,24.6 & 43,35.0 \\ \text { F2 } & 48,19.6 & 29,23.8 & 19,15.4 \\ \text { F3 } & 41,16.7 & 30,24.6 & 11,8.9 \\ \text { F4 } & 10,4.1 & 3,2.5 & 7,5.7\end{array}$

NAFLD activity score (NAS) ${ }^{\mathrm{c}}$

$2.1,1.3$

$2.2,1.4$

$2.1,1.1$

0.256

NAFLD severity score (SAF)

$3.5,2.0$

$3.8,2.2$

3.2, 1.8

0.022

\begin{tabular}{lllll}
\hline Serum levels of cytokines & & & & \\
IL-6 $(\mathrm{pg} / \mathrm{ml})$ & $8.1 \pm 16.5$ & $10.5 \pm 22.7$ & $5.8 \pm 4.3$ & $\mathbf{0 . 0 2 4}$ \\
sIL-6R (ng/ml) & $42.0 \pm 9.3$ & $42.6 \pm 9.3$ & $41.5 \pm 9.3$ & 0.335 \\
Sgp130 (ng/ml) & $316.3 \pm 54.9$ & $317.1 \pm 55.5$ & $315.4 \pm 54.6$ & 0.807 \\
\hline
\end{tabular}

Data is presented as means \pm SD for continuous data and as sample size $(n)$ and percent within the population (\%) for categorical data. $\mathrm{P}$ value for differences between men and women measured by unpaired t-test for continuous data and by Chi square or Fishers exact test for categorical data. Significant findings hold for continuous data with high variability when performing nonparametric sensitivity analysis.

$P$ value for differences between men and women.

${ }^{a}$ for $n$ is 122 for women and 120 for men,

${ }^{\mathrm{b}}$ for $n$ is 122 for women and 121 for men,

${ }^{\mathrm{c}}$ for $n$ is 121 for women and 122 for men. 

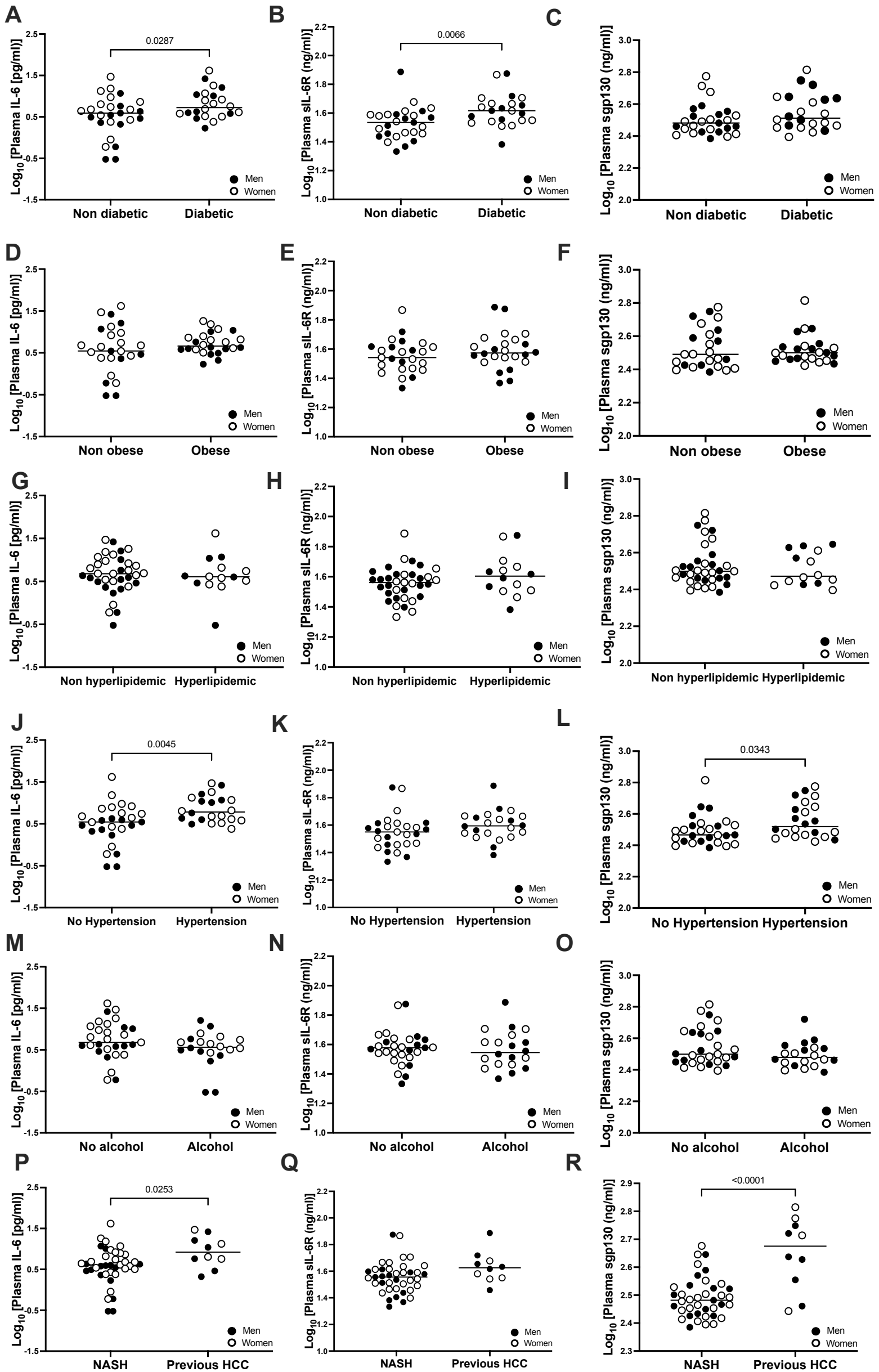
A

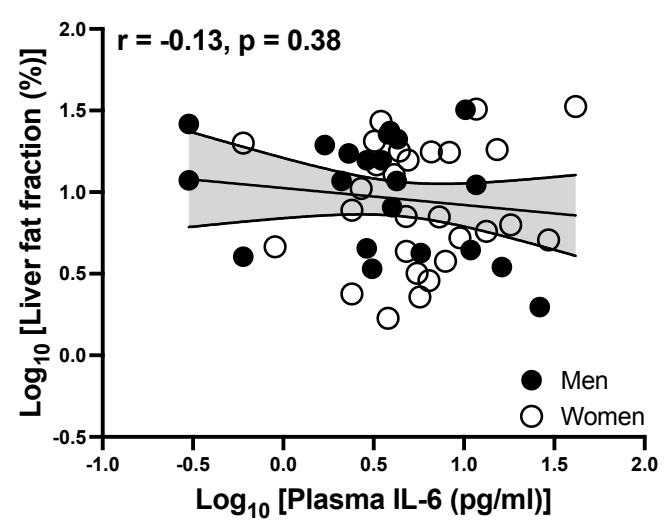

D

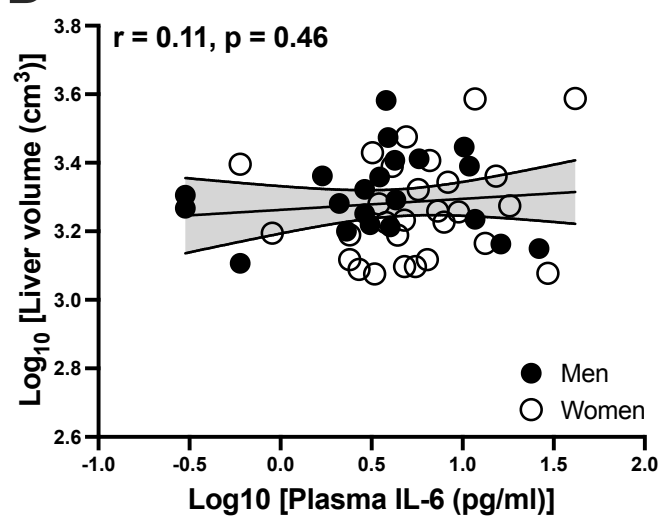

G

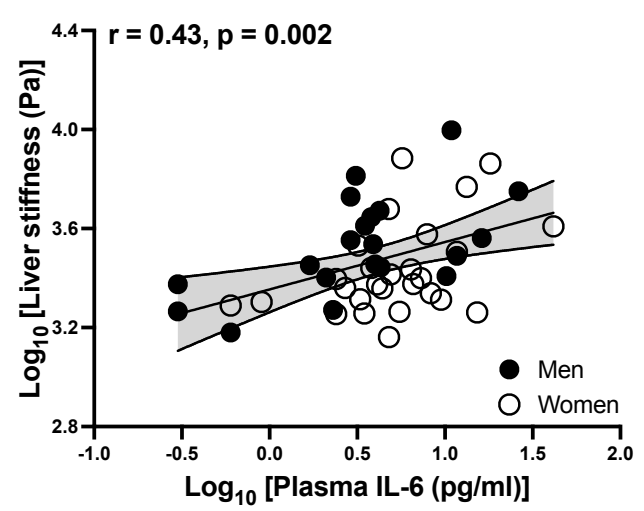

B

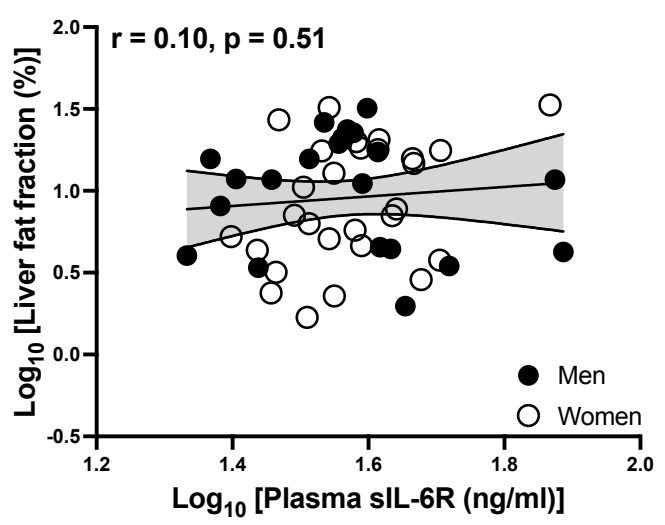

E

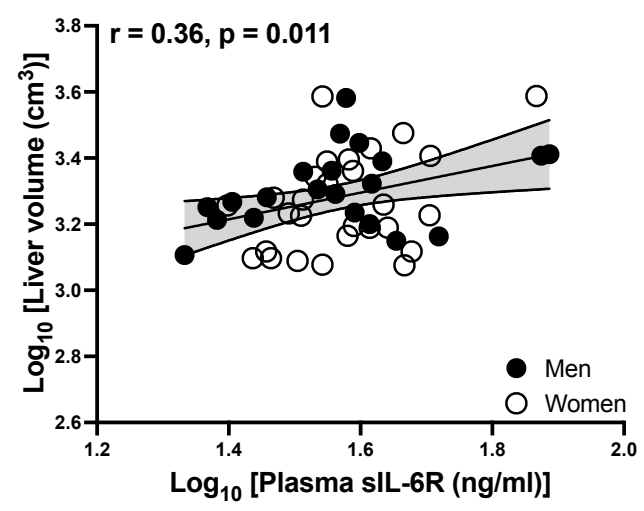

H

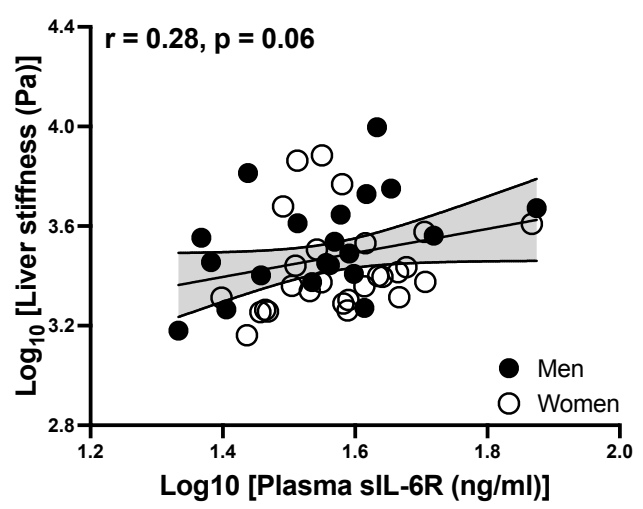

C

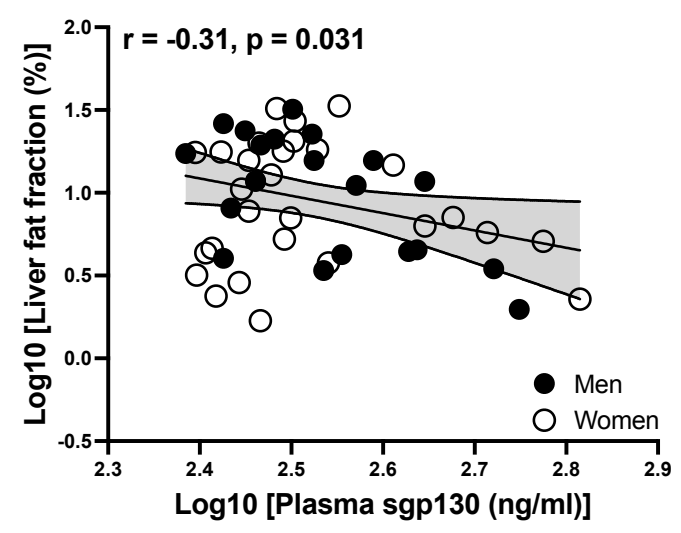

F

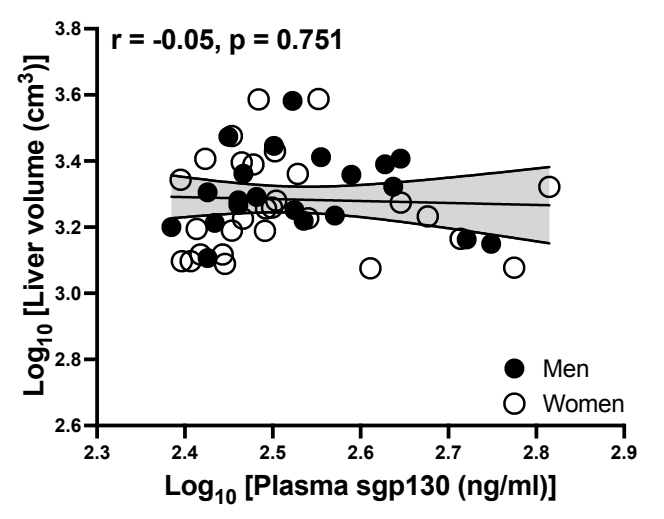

I

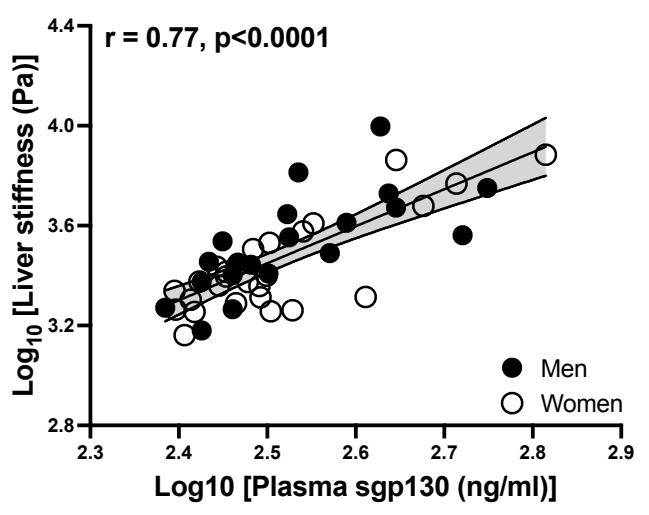



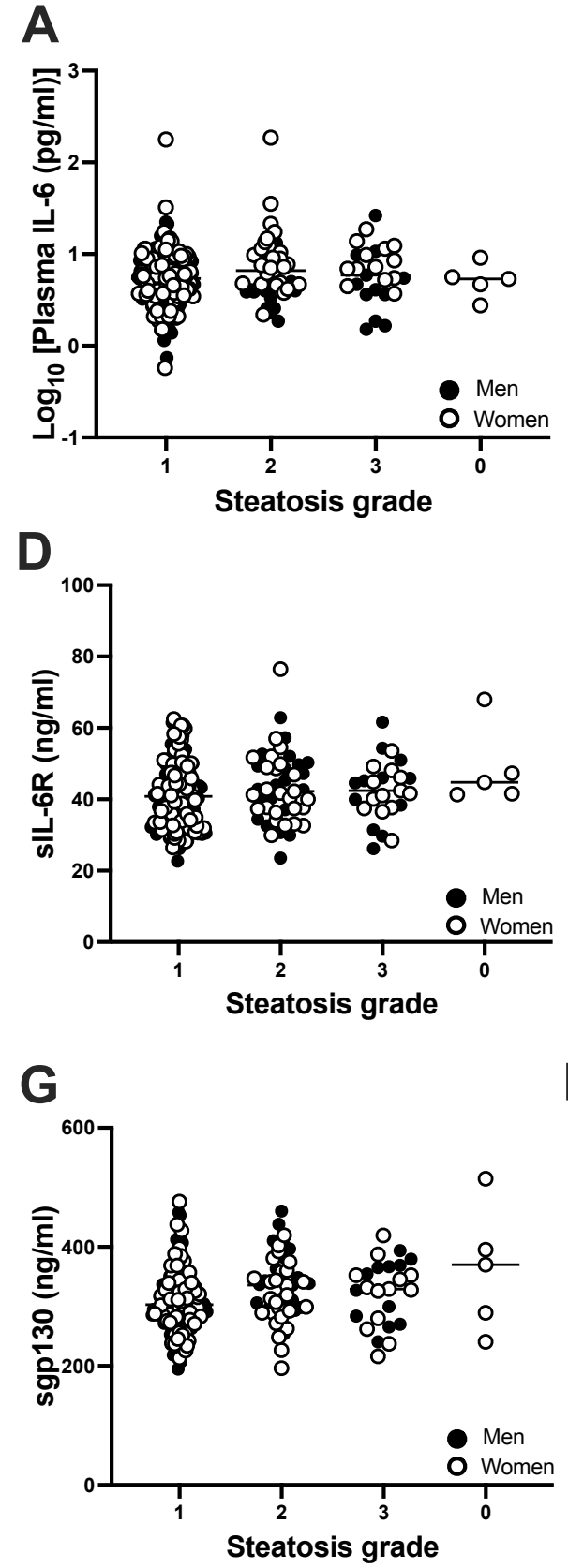

B

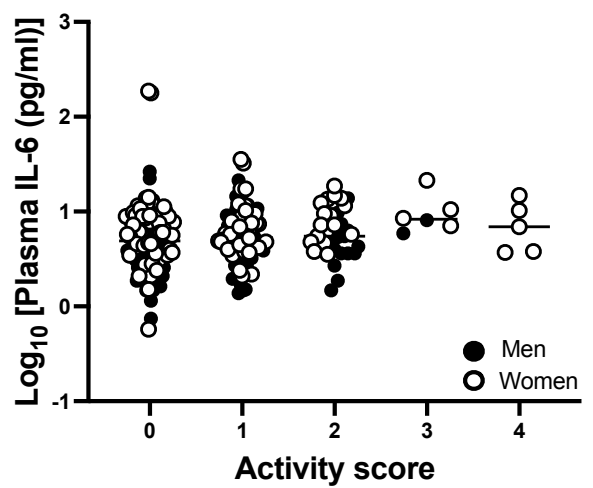

E

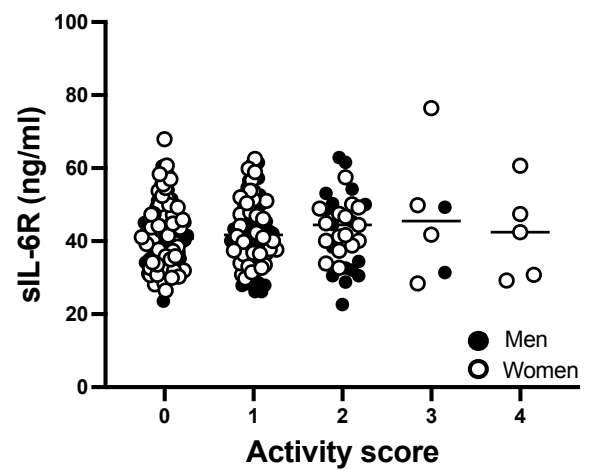

H

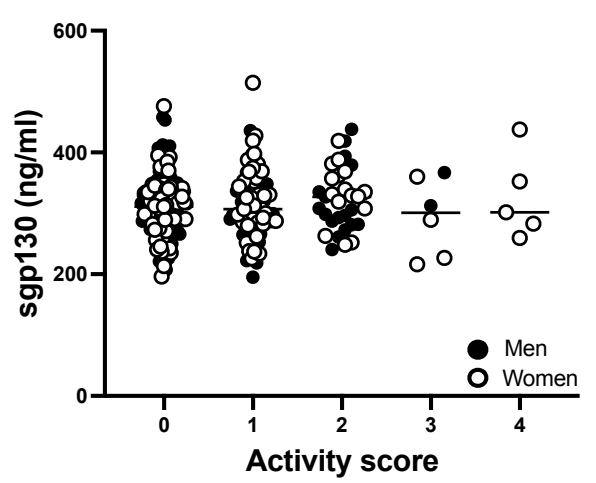

C
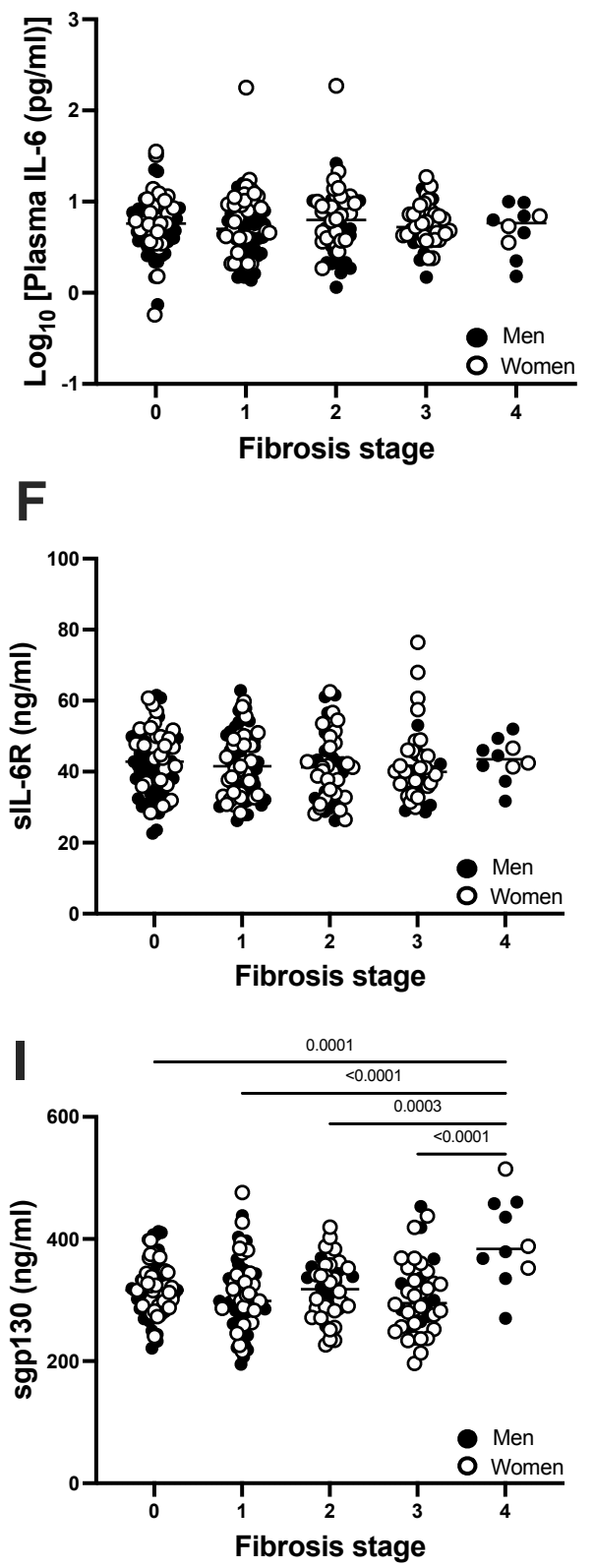
medRxiv preprint doi: https://doi.org/10.1101/2022.01.10.22268968; this version posted January 11, 2022. The copyright holder for this preprint (which was not certified by peer review) is the author/funder, who has granted medRxiv a license to display the preprint in perpetuity.

Supplementary Table 1. Correlations between Log $\log _{10}$ plasma IL-6, slL-6R, sgp130 and

common indicators of liver stiffness/fibrosis in patients with NASH.

\begin{tabular}{|c|c|c|c|c|c|c|}
\hline & \multicolumn{2}{|c|}{ Total $(n=49)$} & \multicolumn{2}{|c|}{ Women $(n=28)$} & \multicolumn{2}{|c|}{$\operatorname{Men}(n=21)$} \\
\hline $\log _{10}[$ Plasma IL-6] & r value & p value & r value & p value & r value & p value \\
\hline Age & 0.31 & 0.031 & 0.22 & 0.272 & 0.42 & 0.059 \\
\hline BMI & 0.34 & 0.018 & 0.35 & 0.067 & 0.50 & 0.122 \\
\hline 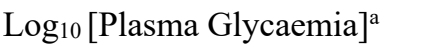 & 0.24 & 0.117 & 0.22 & 0.292 & 0.27 & 0.257 \\
\hline $\log _{10}[\text { Plasma HbA1c }]^{b}$ & 0.25 & 0.090 & 0.16 & 0.429 & 0.35 & 0.129 \\
\hline $\log _{10}[\text { Plasma Triglycerides }]^{c}$ & 0.003 & 0.985 & -0.03 & 0.886 & 0.01 & 0.955 \\
\hline Plasma HDL-c ${ }^{c}$ & -0.16 & 0.291 & -0.34 & 0.094 & -0.13 & 0.597 \\
\hline Plasma LDL-c $^{\mathrm{d}}$ & -0.02 & 0.900 & -0.09 & 0.657 & -0.07 & 0.797 \\
\hline Plasma Cholesterol $^{\mathrm{c}}$ & -0.07 & 0.633 & -0.18 & 0.376 & -0.09 & 0.714 \\
\hline Plasma Hemoglobin ${ }^{\mathrm{e}}$ & -0.32 & 0.027 & -0.19 & 0.352 & -0.37 & 0.111 \\
\hline $\log _{10}[\text { Plasma Globulin }]^{\mathrm{e}}$ & 0.20 & 0.174 & 0.29 & 0.148 & 0.04 & 0.874 \\
\hline $\log _{10}\left[\right.$ Plasma INR-PT] ${ }^{b}$ & 0.30 & 0.046 & 0.41 & 0.038 & 0.36 & 0.117 \\
\hline Platelet count $\mathrm{e}^{\mathrm{e}}$ & -0.28 & 0.059 & -0.31 & 0.110 & -0.53 & 0.015 \\
\hline $\log _{10}[\text { Plasma AST }]^{\mathrm{e}}$ & 0.09 & 0.533 & 0.15 & 0.461 & 0.26 & 0.276 \\
\hline $\log _{10}[\text { Plasma ALT }]^{\mathrm{e}}$ & -0.12 & 0.428 & -0.20 & 0.325 & 0.04 & 0.864 \\
\hline $\log _{10}[\text { Plasma ALP }]^{\mathrm{e}}$ & 0.47 & 0.001 & 0.51 & 0.007 & 0.48 & 0.034 \\
\hline $\log _{10}$ [Plasma Total bilirubin] $^{\mathrm{e}}$ & -0.02 & 0.871 & 0.18 & 0.379 & -0.25 & 0.298 \\
\hline $\log _{10}[\text { Plasma GGT }]^{\mathrm{f}}$ & 0.30 & 0.044 & 0.40 & 0.038 & 0.51 & 0.025 \\
\hline $\log _{10}[\text { Plasma Albumin }]^{\mathrm{e}}$ & -0.56 & $<0.0001$ & -0.57 & 0.002 & -0.56 & 0.011 \\
\hline $\log _{10}[$ Plasma CK-18] & 0.25 & 0.079 & 0.27 & 0.168 & 0.42 & 0.061 \\
\hline NAFLD score ${ }^{f}$ & 0.50 & 0.001 & 0.47 & 0.013 & 0.62 & 0.005 \\
\hline $\log _{10}[\text { FIB-4 index }]^{\mathrm{f}}$ & 0.37 & 0.011 & 0.41 & 0.034 & 0.49 & 0.031 \\
\hline $\log _{10}[\text { APRI score }]^{\mathrm{f}}$ & 0.23 & 0.125 & 0.30 & 0.130 & 0.46 & 0.047 \\
\hline $\log _{10}[\mathrm{sIL-6R}]$ & r value & p value & r value & p value & r value & p value \\
\hline Age & 0.25 & 0.085 & 0.19 & 0.345 & 0.31 & 0.178 \\
\hline BMI & 0.27 & 0.063 & 0.32 & 0.097 & 0.23 & 0.312 \\
\hline 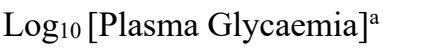 & 0.55 & $<0.0001$ & 0.50 & 0.011 & 0.62 & 0.004 \\
\hline $\log _{10}[\text { Plasma HbA1c }]^{\mathrm{b}}$ & 0.45 & 0.002 & 0.44 & 0.024 & 0.45 & 0.047 \\
\hline $\log _{10}[\text { Plasma Triglycerides }]^{c}$ & 0.37 & 0.011 & 0.37 & 0.065 & 0.38 & 0.107 \\
\hline Plasma HDL-c ${ }^{c}$ & -0.30 & 0.050 & -0.35 & 0.082 & -0.31 & 0.204 \\
\hline Plasma LDL-c ${ }^{\mathrm{d}}$ & -0.25 & 0.109 & -0.25 & 0.228 & -0.30 & 0.234 \\
\hline Plasma Cholesterol $^{\mathrm{c}}$ & -0.15 & 0.329 & -0.24 & 0.232 & -0.10 & 0.963 \\
\hline Plasma Hemoglobin ${ }^{\mathrm{e}}$ & -0.21 & 0.160 & 0.03 & 0.875 & -0.47 & 0.036 \\
\hline $\log _{10}[\text { Plasma Globulin }]^{\mathrm{e}}$ & 0.08 & 0.593 & -0.02 & 0.939 & 0.19 & 0.421 \\
\hline $\log _{10}\left[\right.$ Plasma INR-PT] ${ }^{b}$ & 0.10 & 0.502 & 0.02 & 0.939 & 0.20 & 0.398 \\
\hline Platelet count $\mathrm{t}^{\mathrm{e}}$ & -0.35 & 0.016 & -0.45 & 0.019 & -0.30 & 0.206 \\
\hline $\log _{10}[\text { Plasma AST }]^{e}$ & 0.15 & 0.326 & 0.23 & 0.249 & 0.09 & 0.695 \\
\hline $\log _{10}[\text { Plasma ALT }]^{\mathrm{e}}$ & 0.15 & 0.306 & 0.23 & 0.258 & 0.11 & 0.656 \\
\hline $\log _{10}[\text { Plasma ALP }]^{\mathrm{e}}$ & 0.19 & 0.211 & -0.03 & 0.885 & 0.37 & 0.112 \\
\hline $\log _{10}$ [Plasma Total bilirubin] $^{\mathrm{e}}$ & -0.19 & 0.207 & -0.20 & 0.319 & -0.22 & 0.350 \\
\hline $\log _{10}[\text { Plasma GGT }]^{\mathrm{f}}$ & 0.50 & $<0.001$ & 0.42 & 0.028 & 0.73 & $<0.001$ \\
\hline $\log _{10}[\text { Plasma Albumin }]^{\mathrm{e}}$ & -0.21 & 0.164 & -0.04 & 0.836 & -0.34 & 0.143 \\
\hline $\log _{10}[$ Plasma CK-18] & 0.28 & 0.056 & 0.23 & 0.239 & 0.35 & 0.118 \\
\hline NAFLD score ${ }^{f}$ & 0.47 & 0.001 & 0.52 & 0.006 & 0.43 & 0.070 \\
\hline $\log _{10}[\text { FIB-4 index }]^{f}$ & 0.30 & 0.042 & 0.35 & 0.073 & 0.26 & 0.284 \\
\hline $\log _{10}[\text { APRI score }]^{\mathrm{f}}$ & 0.29 & 0.048 & 0.41 & 0.034 & 0.20 & 0.415 \\
\hline
\end{tabular}


medRxiv preprint doi: https://doi.org/10.1101/2022.01.10.22268968; this version posted January 11, 2022. The copyright holder for this preprint (which was not certified by peer review) is the author/funder, who has granted medRxiv a license to display the preprint in perpetuity.

\begin{tabular}{|c|c|c|c|c|c|c|}
\hline $\log _{10}[\operatorname{sgp} 130]$ & r value & p value & r value & p value & r value & p value \\
\hline Age & 0.53 & $<0.001$ & 0.51 & 0.005 & 0.55 & 0.009 \\
\hline BMI & 0.11 & 0.446 & 0.18 & 0.354 & -0.02 & 0.928 \\
\hline $\log _{10}[\text { Plasma Glycaemia }]^{\mathrm{a}}$ & 0.23 & 0.127 & 0.05 & 0.829 & 0.47 & 0.038 \\
\hline $\log _{10}[\text { Plasma HbA1c }]^{b}$ & 0.25 & 0.090 & 0.09 & 0.664 & 0.46 & 0.041 \\
\hline $\log _{10}[\text { Plasma Triglycerides }]^{c}$ & 0.05 & 0.753 & 0.07 & 0.744 & 0.17 & 0.491 \\
\hline Plasma HDL-c ${ }^{c}$ & -0.27 & 0.075 & -0.29 & 0.154 & -0.21 & 0.381 \\
\hline Plasma LDL-c ${ }^{\mathrm{d}}$ & -0.29 & 0.063 & -0.36 & 0.077 & -0.17 & 0.499 \\
\hline Plasma Cholesterol $^{\mathrm{c}}$ & -0.25 & 0.103 & -0.35 & 0.083 & -0.09 & 0.723 \\
\hline Plasma Hemoglobin ${ }^{\mathrm{e}}$ & -0.32 & 0.028 & -0.27 & 0.180 & -0.49 & 0.029 \\
\hline $\log _{10}[\text { Plasma Globulin] }]^{\mathrm{e}}$ & -0.25 & 0.095 & -0.33 & 0.090 & -0.08 & 0.746 \\
\hline $\log _{10}\left[\right.$ Plasma INR-PT] ${ }^{b}$ & 0.65 & $<0.0001$ & 0.76 & $<0.0001$ & 0.50 & 0.023 \\
\hline Platelet count $\mathrm{e}^{\mathrm{e}}$ & -0.62 & $<0.0001$ & -0.61 & 0.001 & -0.68 & 0.001 \\
\hline $\log _{10}[\text { Plasma AST }]^{\mathrm{e}}$ & 0.28 & 0.057 & 0.23 & 0.244 & 0.35 & 0.126 \\
\hline $\log _{10}[\text { Plasma ALT }]^{\mathrm{e}}$ & -0.12 & 0.436 & -0.26 & 0.197 & 0.02 & 0.930 \\
\hline $\log _{10}[\text { Plasma ALP }]^{\mathrm{e}}$ & 0.62 & $<0.0001$ & 0.49 & 0.009 & 0.80 & $<0.0001$ \\
\hline $\log _{10}[\text { Plasma Total bilirubin }]^{\mathrm{e}}$ & 0.32 & 0.026 & 0.47 & 0.014 & -0.03 & 0.893 \\
\hline $\log _{10}[\text { Plasma GGT }]^{\mathrm{f}}$ & 0.55 & $<0.0001$ & 0.44 & 0.021 & 0.77 & $<0.001$ \\
\hline $\log _{10}[\text { Plasma Albumin] }]^{\mathrm{e}}$ & -0.66 & $<0.0001$ & -0.70 & $<0.0001$ & -0.63 & 0.003 \\
\hline $\log _{10}[$ Plasma CK-18] & 0.38 & 0.007 & 0.38 & 0.045 & 0.39 & 0.084 \\
\hline NAFLD score ${ }^{\mathrm{f}}$ & 0.68 & $<0.0001$ & 0.65 & $<0.001$ & 0.73 & $<0.0001$ \\
\hline $\log _{10}[\text { FIB- } 4 \text { index }]^{\mathrm{f}}$ & 0.70 & $<0.0001$ & 0.73 & $<0.0001$ & 0.68 & 0.001 \\
\hline $\log _{10}[\text { APRI score }]^{\mathrm{f}}$ & 0.63 & $<0.0001$ & 0.55 & 0.003 & 0.62 & 0.005 \\
\hline
\end{tabular}

Statistical analysis was performed using Pearson's correlation.

a, $n$ is 25 for women, 20 for men,

b, $n$ is 26 for women, 20 for men,

c, $n$ is 26 for women, 19 for men,

d, $n$ is 25 for women, 19 for men,

e, $n$ is 27 for women, 20 for men,

f, $n$ is 27 for women, 19 for men. 
Biopsy confirmed

NASH patients $=493$

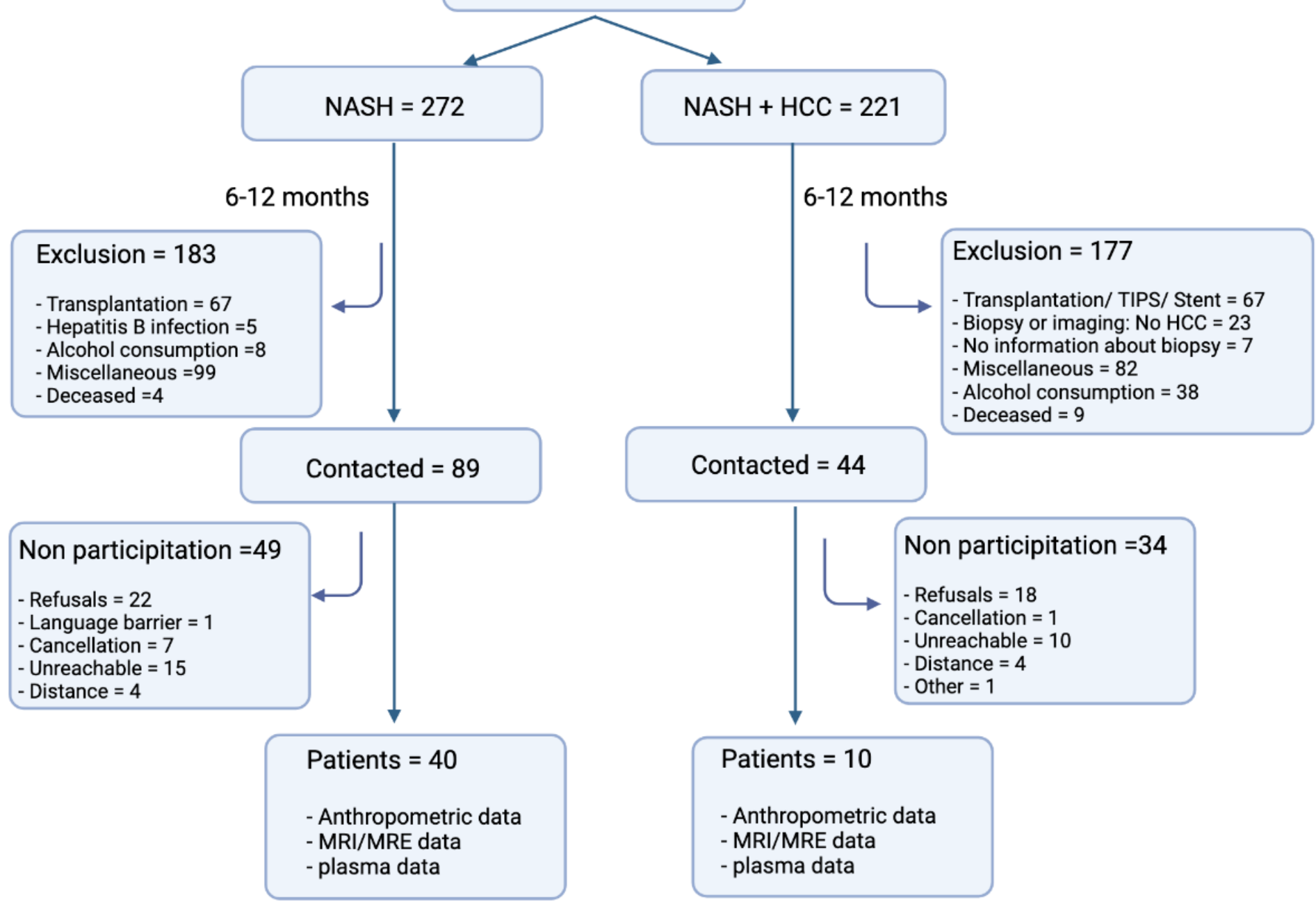

Supplementary Figure 1. Study design for NASH cohort. Between May 2018 and June 2019, eligible patients with a history of biopsy-confirmed NASH were contacted to participate in our study. Flow chart details the inclusion and exclusion criteria used, as well as reasons for non-participation. Consenting patients $(\mathrm{N}=50)$ returned to the Centre hospitalier de l'Université de Montréal for MRE/ MRI scan and blood draw. 


\section{A \\ B It is made available under a CC-BY C-ND 4.0 International license.}
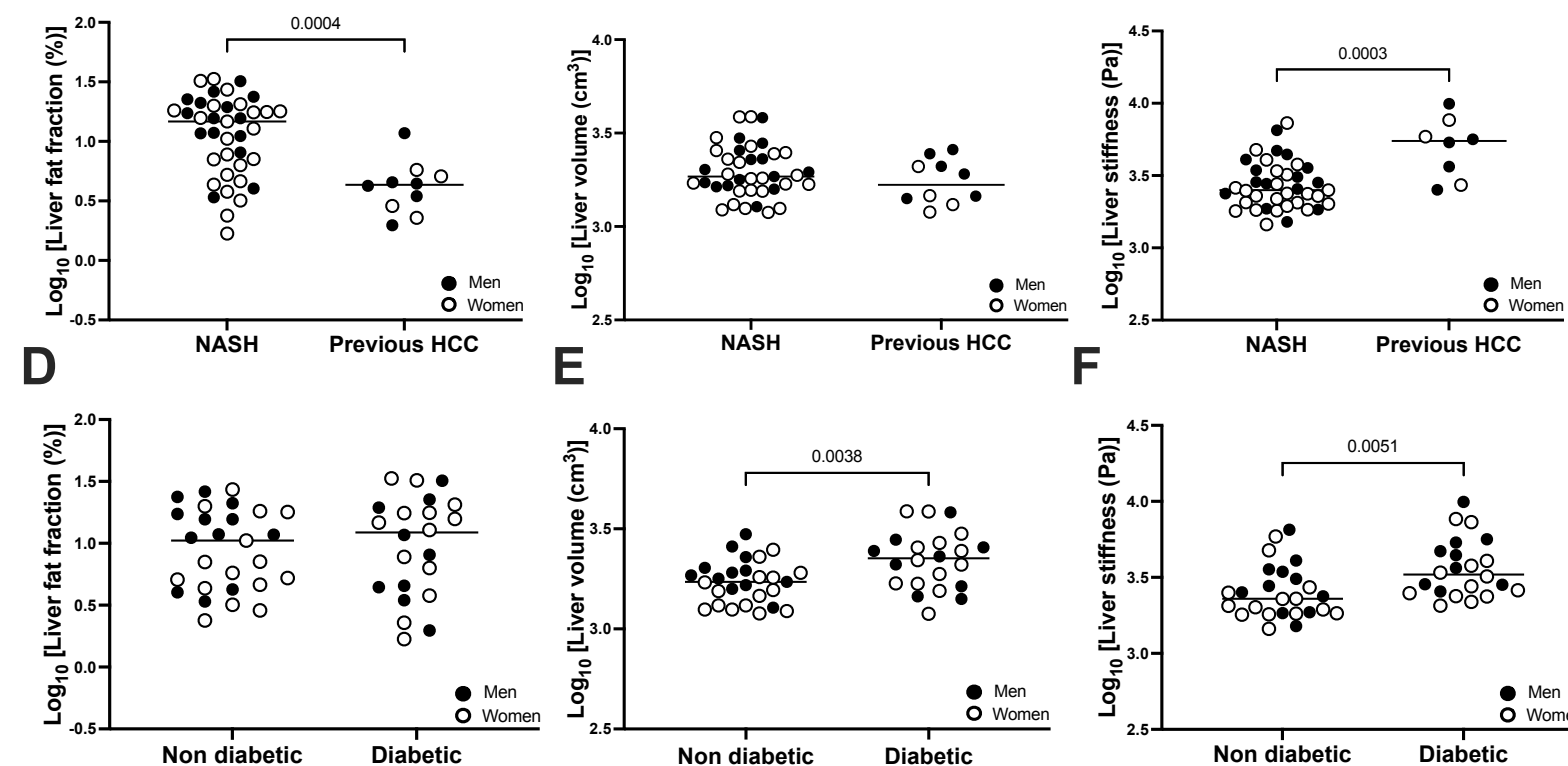

G

J
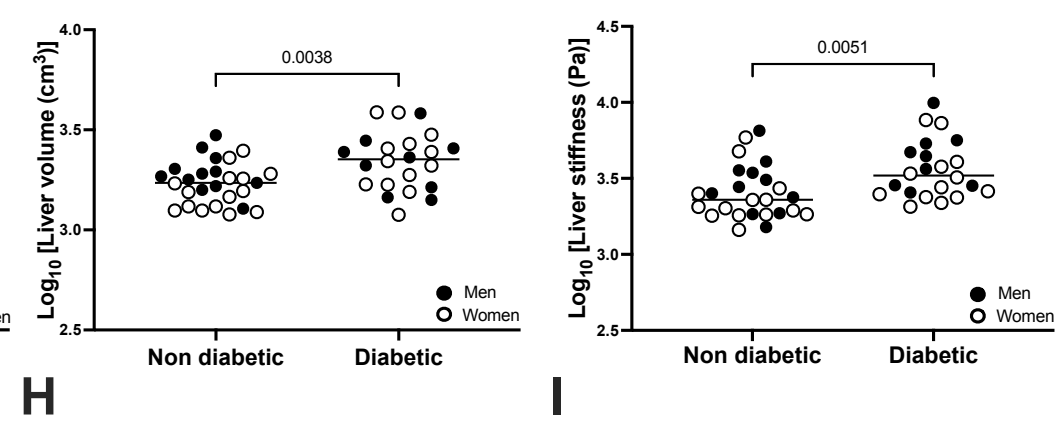

\section{,}

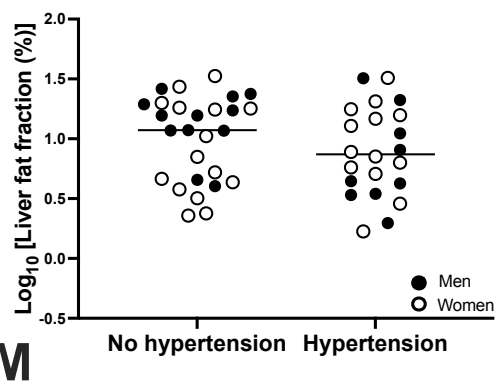

P

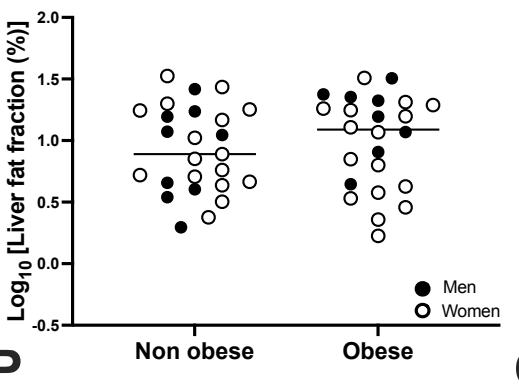

ฮั̊

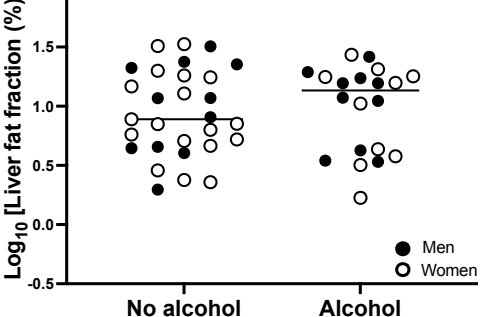

No alcohol
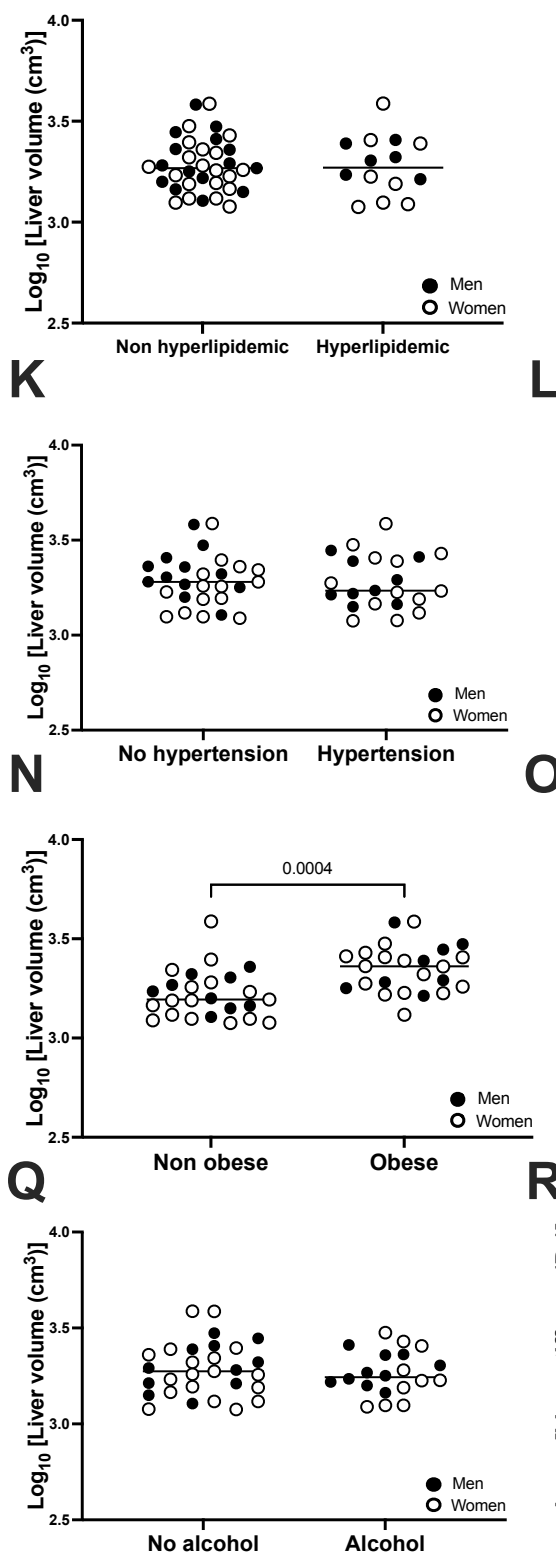
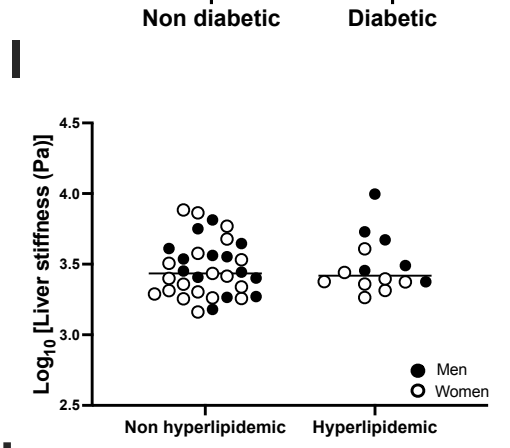

L
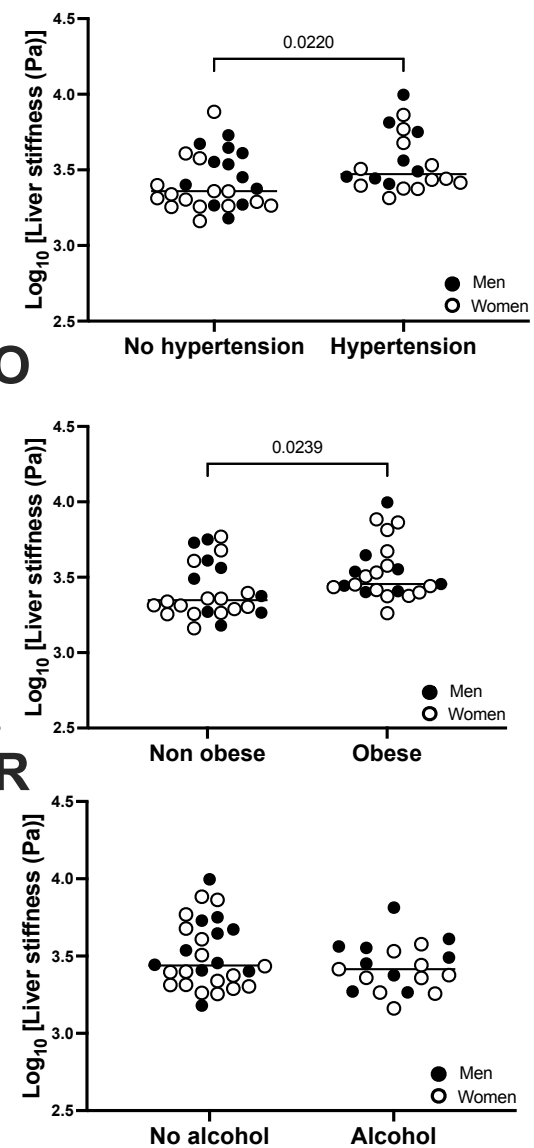

Supplementary Figure 2. MRE/MRI measures of Liver fat fraction, volume and stiffness in patients with NASH with or without previous history of HCC (A-C), diabetes (D-F), hyperlipidemia (G-I), hypertension (J-L), obesity (M$\mathrm{O})$ and alcohol consumption (P-R). Data is presented as the distribution around the mean. Statistical significance was evaluated by un-paired $t$ test. For liver fat fraction and liver volume, $n=28$ women (open circles) and $n=21$ men (closed circles). For liver stiffness, n=27 women (open circles) and n=20 men (closed circles). 
A

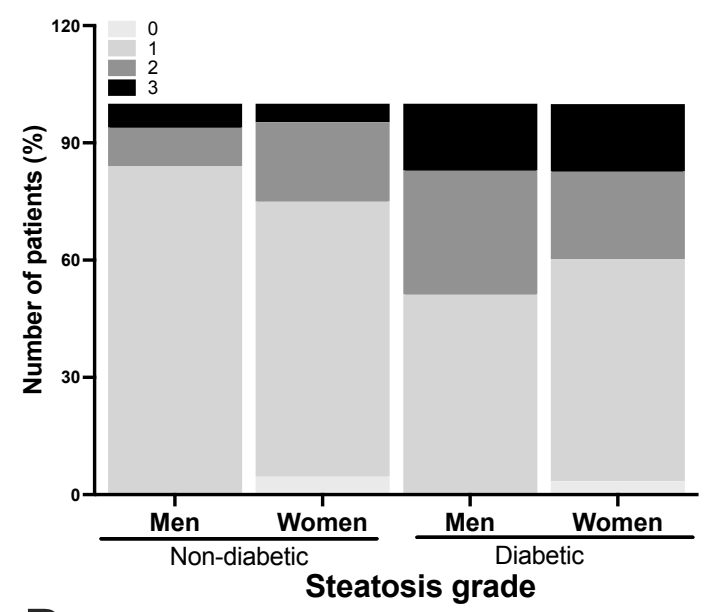

D

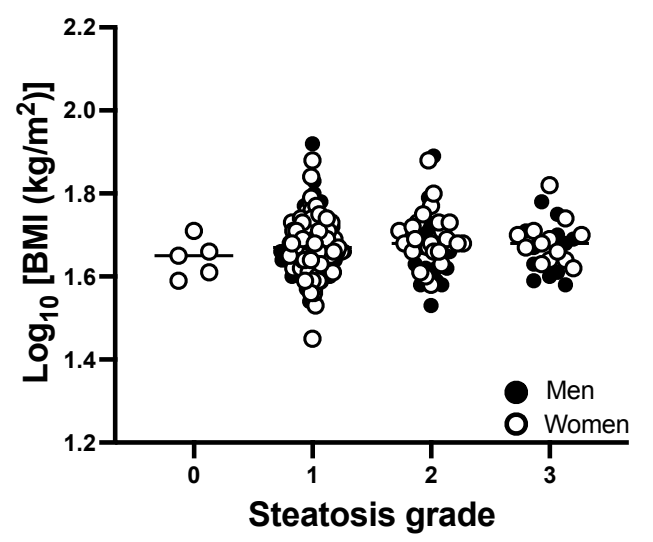

G

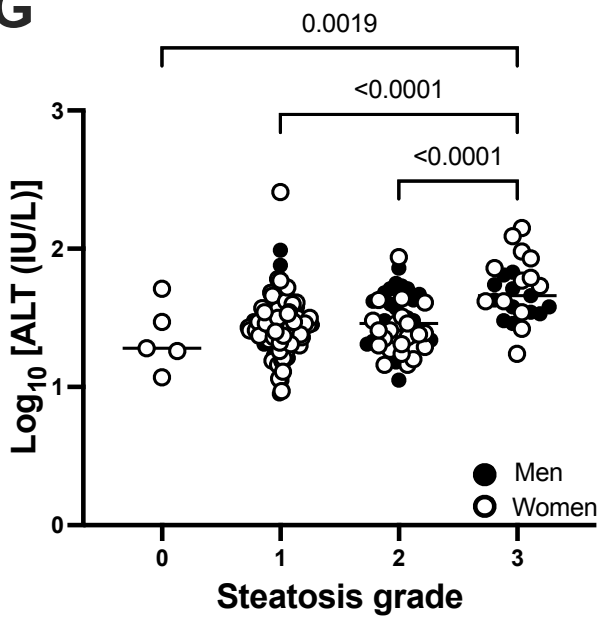

B

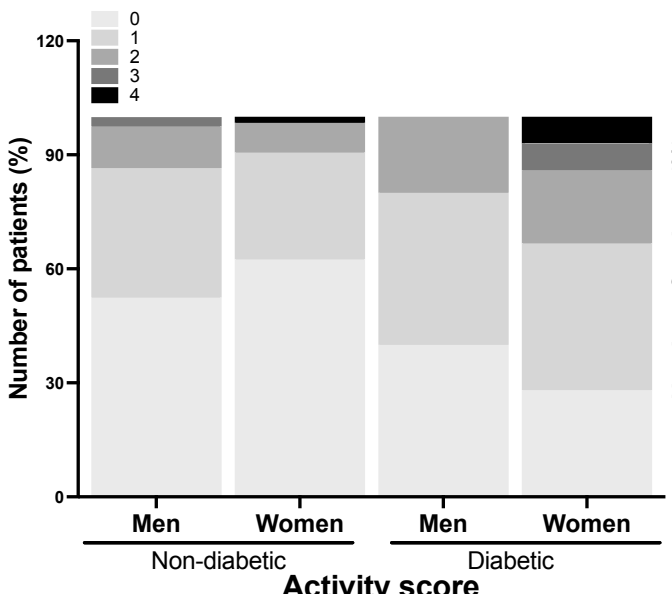

$\mathbf{E}$

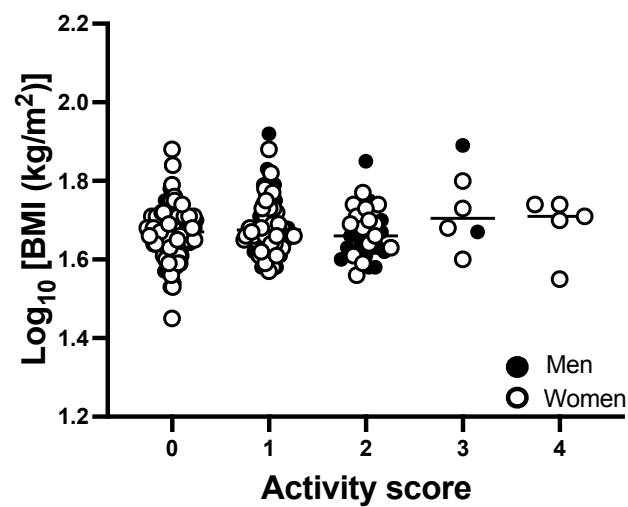

H

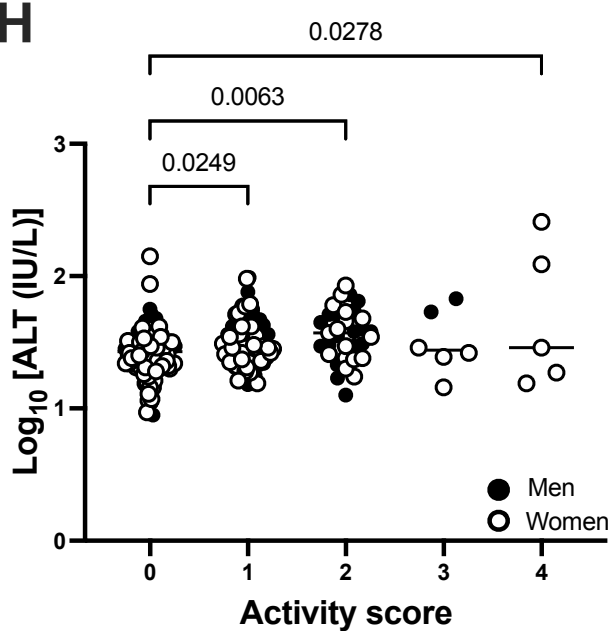

C

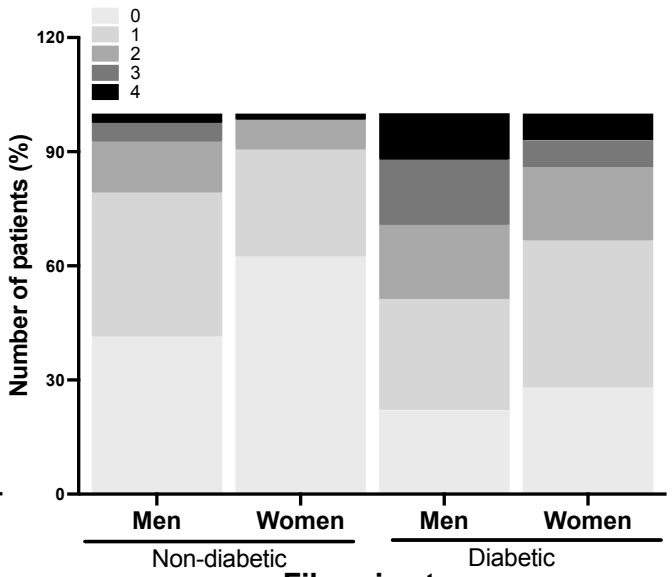

Fibrosis stage

E

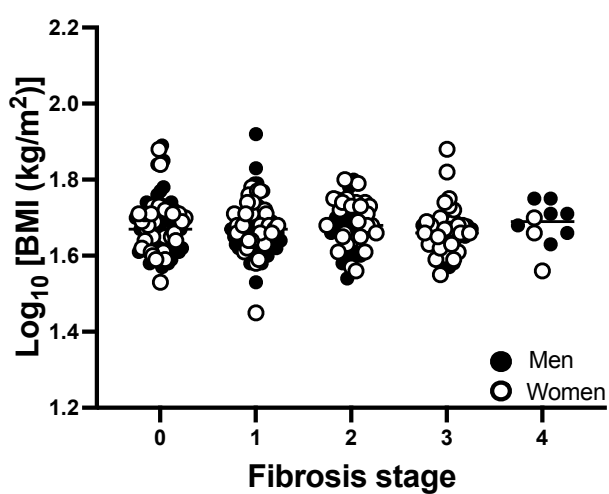

I

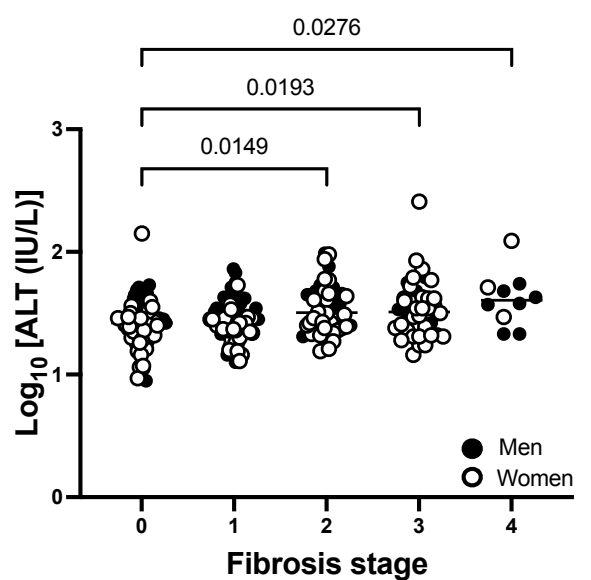

Supplementary Figure 5. Liver steatosis grade, activity score and fibrosis stage in patients with morbid obesity with or without diabetes $(A, D, G)$, BMI $(B, E, H)$, and plasma $A L T$ concentrations $(C, F, I)$ in relative to various levels of steatosis grade $G 0(n=5), G 1(n=168), G 2(n=47), G 3(n=25)$, activity score $A 0(n=115), A 1(n=84), A 2$ $(n=33), A 3(n=6), A 4(n=5)$ and fibrosis stage F0 $(n=73), F 1(n=73), F 2(n=48), F 3(n=41), F 4(n=10)$ determined by histology. Data is presented as the distribution around the mean. Analysis performed by One-way Anova with multiple comparisons. Analysis was adjusted for age, sex, BMl and diabetes. For activity score $\mathrm{N}=121$ women (open circles) and $\mathrm{N}=122$ men (closed circles). 


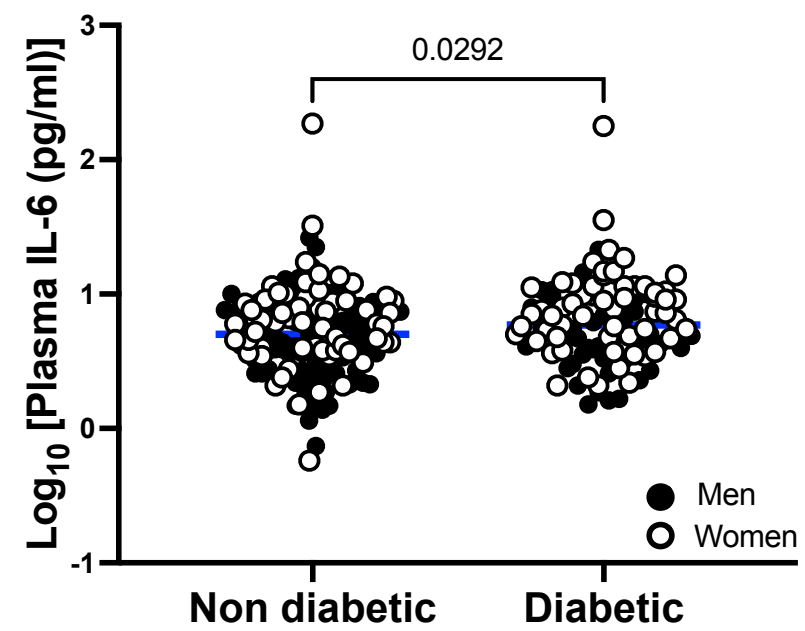

B

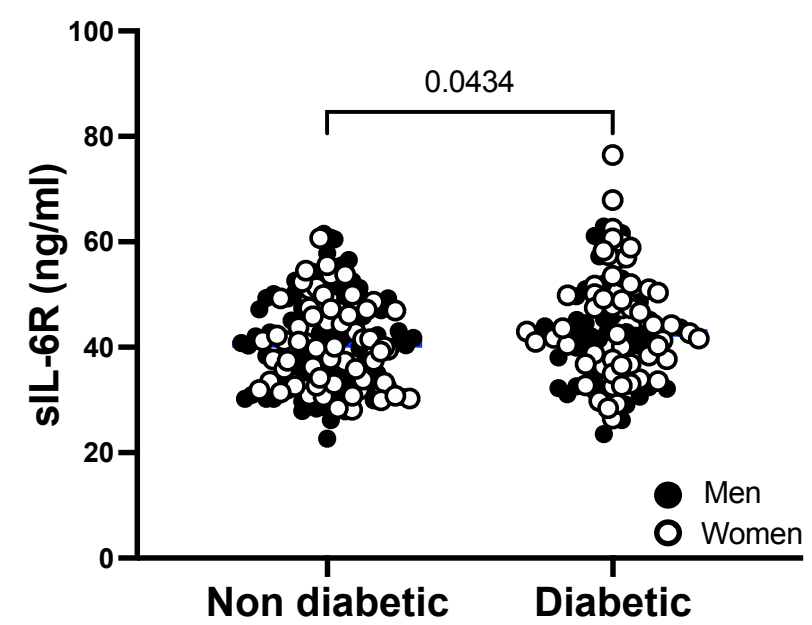

C

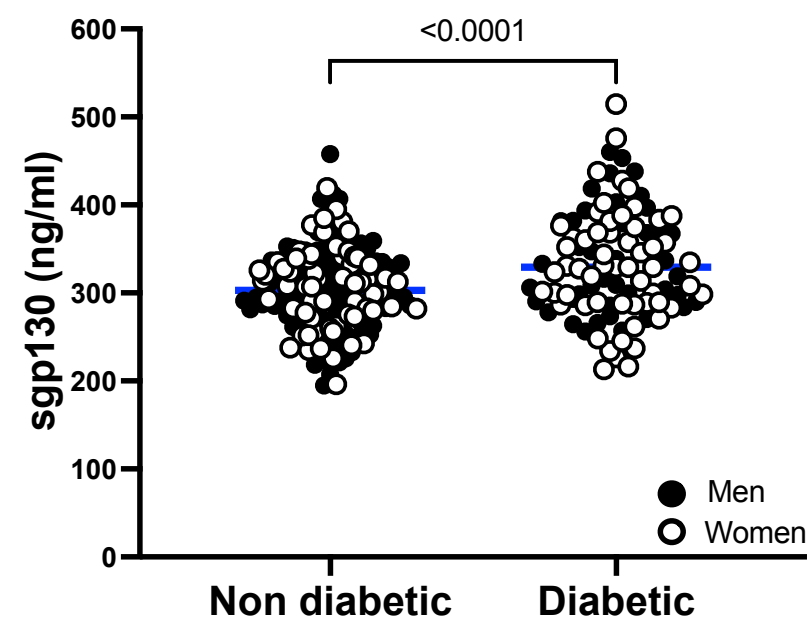

Supplementary Figure 6. Plasma levels of IL-6 (A), sIL-6R (B) and sgp130 (C) in patients with morbid obesity stratified by diagnosis of diabetes. Data is presented as the distribution around the mean. Statistical significance was evaluated by unpaired $t$ test. 


\section{The REMARK checklist}

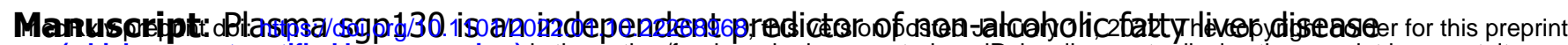

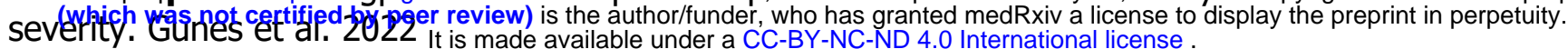

\begin{tabular}{|c|c|}
\hline \multicolumn{2}{|c|}{ Item to be reported } \\
\hline 1 & State the marker examined, the study objectives, and any pre-specified hypotheses. \\
\hline \multicolumn{2}{|c|}{ MATERIALS AND METHODS } \\
\hline \multicolumn{2}{|c|}{ Patients } \\
\hline 2 & $\begin{array}{l}\text { Describe the characteristics (e.g., disease stage or co-morbidities) of the study patients, } \\
\text { including their source and inclusion and exclusion criteria. }\end{array}$ \\
\hline 3 & Describe treatments received and how chosen (e.g., randomized or rule-based). \\
\hline \multicolumn{2}{|c|}{ Specimen characteristics } \\
\hline 4 & $\begin{array}{l}\text { Describe type of biological material used (including control samples) and methods of } \\
\text { preservation and storage. }\end{array}$ \\
\hline \multicolumn{2}{|c|}{ Assay methods } \\
\hline 5 & $\begin{array}{l}\text { Specify the assay method used and provide (or reference) a detailed protocol, including } \\
\text { specific reagents or kits used, quality control procedures, reproducibility assessments, } \\
\text { quantitation methods, and scoring and reporting protocols. Specify whether and how } \\
\text { assays were performed blinded to the study endpoint. }\end{array}$ \\
\hline
\end{tabular}

Study design

$6 \quad$ State the method of case selection, including whether prospective or retrospective and whether stratification or matching (e.g., by stage of disease or age) was used. Specify the time period from which cases were taken, the end of the follow-up period, and the median follow-up time.

$7 \quad$ Precisely define all clinical endpoints examined.

$8 \quad$ List all candidate variables initially examined or considered for inclusion in models.

$9 \quad$ Give rationale for sample size; if the study was designed to detect a specified effect size, give the target power and effect size.

Statistical analysis methods

10 Specify all statistical methods, including details of any variable selection procedures and other model-building issues, how model assumptions were verified, and how missing data were handled.

11

Clarify how marker values were handled in the analyses; if relevant, describe methods used for cutpoint determination.

\section{RESULTS}

Data

12 Describe the flow of patients through the study, including the number of patients included in each stage of the analysis (a diagram may be helpful) and reasons for dropout. Specifically, both overall and for each subgroup extensively examined report the numbers of patients and the number of events.

Report distributions of basic demographic characteristics (at least age and sex), standard (disease-specific) prognostic variables, and tumor marker, including numbers of missing values.

\section{Analysis and presentation}

14 Show the relation of the marker to standard prognostic variables.
Page no.

Pg. 6

Pg. 7, 8, 9,

Table 1, 5,

Supplementary

Figure 1

N/A

Pg. 7, 8, 9

Pg. 9

$\&$ details in

figure/table

legends.

Pg. 7,8

Pg. 10

Pg. 7, 8, 9

Pg. 9, 10

Pg. 9, 10

Pg. 7, 8, 9

Supplementary figure 1

(+ details in all other

tables/figures)

Pg. 7, 8, 9

(+ details in all other

tables/figures)

Pg. 13, 14, 15

Table 2, 3, 4,

Supplementary

Table 1

Pg. 13, 14, 15

+ See all tables

Source: McShane LM, Altman DG, Sauerbrei W, Taube SE, Gion M, Clark GM: Reporting recommendations for tumor marker prognostic studies (REMARK). J Natl Cancer Inst 2005; 97: 1180-1184. 


\section{The REMARK checklist}

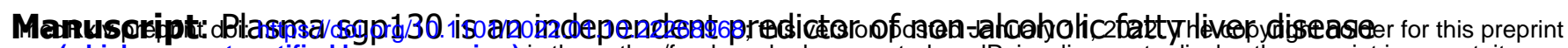

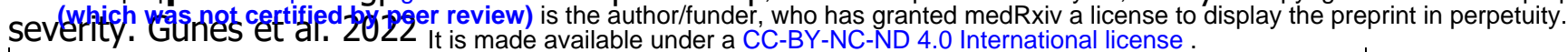
similar analyses for all other variables being analyzed. For the effect of a tumor marker on a time-to-event outcome, a Kaplan-Meier plot is recommended. confidence intervals for the marker and, at least for the final model, all other variables in the model.

17 Among reported results, provide estimated effects with confidence intervals from an analysis in which the marker and standard prognostic variables are included, regardless of their statistical significance.

18 If done, report results of further investigations, such as checking assumptions, sensitivity analyses, and internal validation.

\section{DISCUSSION}

19 Interpret the results in the context of the pre-specified hypotheses and other relevant studies; include a discussion of limitations of the study.

20 Discuss implications for future research and clinical value.

Pg. 14, Table 4

Pg. 13, 14, 15

+ See all tables

N/A

Pg. $16,17,18$

Pg. 18 